\title{
LAS INSTITUCIONES RUSAS DE REPRESENTACIÓN DURANTE LOS SIGLOS XVI Y XVII EN EL CONTEXTO EUROPEO: UNA PERSPECTIVA HISTORIOGRÁFICA
}

\section{Russian Representative Institutions of the $16^{\text {th }}-17^{\text {th }}$ Centuries in the European Context: A Historiographical Perspective}

\section{Vladislav Dmítrievich NAZÁROV}

Instituto de Historia Universal de la Academia de Ciencias de Rusia, Moscú

Correo-e: vnaz@zmail.ru

Pável Yúrievich OUVÁROV

Instituto de Historia Universal de la Academia de Ciencias de Rusia, Moscú Correo-e: oupav@mail.ru

\section{Vladímir Aleksándrovich VÉDYUSHKIN}

Instituto de Historia Universal de la Academia de Ciencias de Rusia, Moscú Correo-e: vedyushkin@mail.ru

RESUMEN: En el artículo se analiza la historia del surgimiento y desarrollo de las instituciones representativas en Rusia: los Zemskie Sobory, sus principales características y diferencias respecto a las instituciones correspondientes de Europa Occidental. Se identifican las líneas básicas de la historia de Rusia que determinaron la naturaleza y la dinámica del desarrollo de los Zemskie Sobory, término que traducido literalmente significa la «Asamblea de la Tierra». Se muestra la conexión entre su auge, la situación específica de la sociedad y el Estado rusos durante el Período de los Tumultos, revisándose algunas fuentes primarias sobre el tema. La mayor atención se dedica a los estudios rusos sobre la historia de las instituciones representativas en Rusia y en Europa Occidental. Se analiza el interés permanente 
VLADISLAV DMÍTRIEVICH NAZÁROV, PÁVEL YÚRIEVICH OUVÁROVY VLADÍMIR ALEKSÁNDROVICH VÉDYUSHKIN LAS INSTITUCIONES RUSAS DE REPRESENTACIÓN DURANTE LOS SIGLOS XVI Y XVII EN EL CONTEXTO EUROPEO: UNA PERSPECTIVA HISTORIOGRÁFICA

en la experiencia histórica europea, tan inherente al pensamiento y a la tradición historiográfica rusas. En este contexto se analizan las causas del surgimiento y larga existencia del término técnico «la monarquía estamental representativa», muy característico para la historiografía rusa. Se distinguen y determinan las etapas principales en los estudios rusos sobre las instituciones representativas desde mediados del siglo XIx hasta nuestros días. Se examinan los resultados científicos del Congreso realizado en Moscú en 2013, dedicado a las instituciones representativas en Rusia en el contexto de la historia europea; finalmente, se trazan las perspectivas para futuras investigaciones sobre el tema.

Palabras clave: Zemskie Sobory; instituciones representativas; Rusia, Europa Occidental; historiografía; Edad Media; Alta Edad Moderna.

ABSTRACT: The article deals with the history of the origins and development of Zemsky Sobors - Russian representative institutions, their main features and differences from corresponding bodies in Western Europe. It marks out those traits of Russian history that determined the character and development dynamics of Zemsky Sobors, shows a connection between their heyday and specific condition of Russian society and state during the Time of Troubles, and describes some sources for this subject. The focus of the article is on Russian research of the history of representative institutions in Russia and Western Europe. It also investigates a close attention to European historical experience, inherent in the Russian social thought. In this context reasons for the origin and existence of the term of «estaterepresentative monarchy», characteristic for the Russian historiography, are analysed. And the main periods of the study of representative institutions from the mid-19th century to the present day are determined and characterised. The article considers the outcome of a Moscow conference of 2013 devoted to the representative Institutions of Russia in the european context and outlines perspectives of further research.

Key words: Zemsky Sobors; Representative Bodies; Russia; Western Europe; Historiography; Middle Ages; Early Modern Period.

El motivo principal que impulsó la publicación de este dossier fue el Congreso celebrado en Moscú en 2013 y dedicado a la representatividad estamental rusa de los siglos XVI y XVII en el contexto europeo. El año trece es muy significativo en la historia de Rusia. Ante todo, es el primer año del reinado de Mikhaíl Fiódorovich, el primer zar de la última dinastía de Rusia, la de los Románov. Por esta razón, se celebraron en Rusia muchas actividades conmemorativas. La apelación al pasado 
VLADISLAV DMÍTRIEVICH NAZÁROV, PÁVEL YÚRIEVICH OUVÁROV Y VLADÍMIR ALEKSÁNDROVICH VÉDYUSHKIN LAS INSTITUCIONES RUSAS DE REPRESENTACIÓN DURANTE LOS SIGLOS XVI Y XVII EN EL CONTEXTO EUROPEO: UNA PERSPECTIVA HISTORIOGRÁFICA

monárquico es un rasgo importante de la conciencia histórica rusa durante los últimos años. El reinado de Mikhaíl comenzó con su elección como zar de Rusia por el Zemski Sobor (Asamblea Nacional) el 21 de febrero de 1613, lo que significó el comienzo de la salida del estado de crisis social y política, acompañada por la primera guerra civil en la historia de Rusia y conocida bajo el nombre de Smuta o Período de los Tumultos.

El hecho mismo de la elección del zar por la Asamblea inspiró a los historiadores a investigar la particularidad de la cultura política rusa y sus instituciones representativas, cuyo florecimiento data de la primera mitad y mediados del siglo XVII. Por eso parece natural la necesidad de realizar estudios comparativos, de cotejo y equiparación de la experiencia rusa con las instituciones representativas típicas para la cultura política de los otros países europeos del momento.

Para el pensamiento y la tradición historiográfica rusa, es inherente el interés permanente en la experiencia histórica europea, así para comparar con la realidad rusa, como para estudiar la historia de Europa occidental en sí misma. La tradición historiográfica sobre la historia europea medieval y moderna fue muy fuerte en Rusia desde la segunda mitad del siglo xIX. Por ejemplo, se constituyó una destacada escuela dedicada a la historia agraria de Inglaterra representada por nombres como Pável Vinográdov, Dmitry Petrushevsky y Aleksandr Savin (y continuada en la época soviética por Evgueny Kosminsky, Mikhaíl Barg y otros investigadores). Los logros de los historiadores rusos fueron tan señalados, que el lugar elegido para la celebración del Congreso Mundial de Ciencias Históricas de 1918 fue San Petersburgo.

Es evidente que la Primera Guerra Mundial y la Revolución en Rusia alteraron estos planes, pero para la ciencia histórica marxista que prevaleció en la URSS a mediados de los años treinta, era muy lógico el interés hacia la historia occidental. Puesto que se trataba de procesos históricos, universales y lógicos, del desarrollo y cambio de las formaciones socio-económicas, el ejemplo europeo servía no como paradigma particular, sino universal, aplicable a todas las sociedades que se encontraban en un nivel análogo de desarrollo. La historia europea estaba mejor reflejada en las fuentes y mejor investigada, por eso su ejemplo resultaba más conveniente para investigar los rasgos característicos de la base feudal y, más todavía, de la superestructura (es decir, del estado) y del proceso de su evolución a finales de la «época feudal».

Se debe precisar que para la historiografía soviética (y, más ampliamente, marxista) fue significativa la introducción de una división específica en períodos. La Edad Media se caracterizaba como el tiempo del surgimiento, florecimiento y declinación de la «formación feudal». La «superestructura» (el estado feudal, la ideología, el derecho, la religión, la cultura, etc.) correspondía a la base económica de la formación (el modo de producción feudal, la propiedad feudal de la tierra). 
VLADISLAV DMÍTRIEVICH NAZÁROV, PÁVEL YÚRIEVICH OUVÁROV Y VLADÍMIR ALEKSÁNDROVICH VÉDYUSHKIN LAS INSTITUCIONES RUSAS DE REPRESENTACIÓN DURANTE LOS SIGLOS XVI Y XVII EN EL CONTEXTO EUROPEO: UNA PERSPECTIVA HISTORIOGRÁFICA

Como fin del feudalismo se consideraban «las revoluciones burguesas», y se disputaba la importancia de cada una de ellas como el jalón principal en el tránsito del feudalismo al capitalismo: la «Revolución de los Países Bajos» (el equivalente marxista de la Guerra de los Ochenta años), la «Revolución Inglesa» de mediados del siglo Xvir o la «Revolución Francesa». Por fin, a mediados de los años treinta los políticos soviéticos de más alto nivel decidieron, sin ninguna conexión con las disputas científicas, considerar a la «Revolución Inglesa» como un hito convencional entre el feudalismo y el capitalismo. Desde este momento (y hasta finales de la época soviética), el período comprendido desde finales del siglo xv hasta mediados del XviI se consideraba en la historiografía soviética, a diferencia de lo característico en los países occidentales, como la Baja Edad Media ${ }^{1}$. El absolutismo se trataba como la última fase del estado feudal. El carácter paradójico de esta periodización tenía sus ventajas (por ejemplo, permitía evitar una ruptura entre los estudios de los medievalistas y de los modernistas). En todo caso, los nombres de los historiadores soviéticos especialistas en la Baja Edad Media (según la denominación marxista), tales como Borís Pórshnev, Aleksandra Lúblinskaya o Moisey Smirin, eran conocidos bastante bien entre los historiadores de Europa occidental gracias a las traducciones de sus libros y a sus intervenciones en los grandes congresos internacionales de historia ${ }^{2}$. Respecto a las otras regiones del mundo se reconocía la posibilidad del tránsito más tardío del feudalismo al capitalismo. Desde este punto de vista, para la historia rusa la abolición de la servidumbre en 1861 y las reformas liberales del reinado de Alejandro II se consideraban el fin de la época feudal. A su vez, estas reformas eran preparadas por el desarrollo del capitalismo en la primera mitad del siglo xix. Por eso no es asombroso que en época soviética los departamentos de «historia de la URSS durante el período del feudalismo» unieran a los historiadores que investigaban una época milenaria, desde el siglo IX hasta comienzos del xIx.

Las periodizaciones rechazadas en época soviética fueron restablecidas desde los años 90, y ahora cada investigador puede elegir la periodización a seguir. Pero la enseñanza, sobre todo en la escuela secundaria, requiere un punto de vista unificado, y los autores de los manuales volvieron al punto de vista de la

1. No todos los historiadores soviéticos compartían este punto de vista; algunos profesores universitarios se permitían libertades a la hora de explicar a los alumnos las ventajas y defectos de las distintas periodizaciones, guiándoles hacia sus propias opiniones, a veces muy diferentes de las oficiales.

2. Porchnev, B.: Les soulèvements populaires en France de 1623 à 1648. París, 1963; LublinsKaYA, A. D.: French Absolutism: the Crucial Phase 1620-1629. Londres, Cambridge University Press, 1968; LublinskaYA, A. D.: La crisis del siglo XVII y la sociedad del Absolutismo / prólogo de Josep Fontana. Barcelona, 1979 (2 ${ }^{\mathrm{a}}$ ed. 1983); SMIRIN, M. M.: Die Volksreformation des Thomas Münzer und der grosse Banernkrieg. Berlín, 1952. 
VLADISLAV DMÍTRIEVICH NAZÁROV, PÁVEL YÚRIEVICH OUVÁROV Y VLADÍMIR ALEKSÁNDROVICH VÉDYUSHKIN LAS INSTITUCIONES RUSAS DE REPRESENTACIÓN DURANTE LOS SIGLOS XVI Y XVII EN EL CONTEXTO EUROPEO: UNA PERSPECTIVA HISTORIOGRÁFICA

historiografía occidental (compartida por los historiadores rusos de comienzos del siglo xx $)^{3}$.

Muchos historiadores rusistas de los siglos XIX y Xx han manifestado un interés sincero hacia la experiencia europea, pero aquí es necesario hacer ciertas puntualizaciones. Algunos historiadores del siglo xIx estaban convencidos de que Rusia tenía su vía histórica especial de desarrollo y que la historia rusa era incomparable con la historia de los países occidentales o no necesitaba tal comparación. Pero muchos otros profesores de las universidades imperiales rusas eran liberales y pensaban que Rusia pertenecía a la familia de los pueblos europeos y se movía por el camino del progreso social y político a la par que ellos, aunque quedaba un poco atrasada en este proceso.

Durante las tentativas de las reformas liberales, el interés hacia la experiencia del «gobierno del pueblo» (narodopravstvo) de la Edad Media y Moderna creció mucho. Por un lado, los historiadores eslavófilos veían en el veche (asamblea popular de los ciudadanos de Nóvgorod y de otras ciudades rusas en la época medieval) el origen de la democracia, presuntamente propia para la sociedad rusa tradicional. Por otro lado, las instituciones representativas de Europa occidental (tales como el Parlamento inglés, los Estados Generales franceses o las Cortes castellanas) atrajeron mucha atención. A comienzos del siglo xx, cuando Rusia se transformaba de una monarquía autocrática en una monarquía parlamentaria, el libro de Wladimiro Piskorski «Las Cortes de Castilla en el período de tránsito de la Edad Media a la Moderna: 1188-1520» se percibía de gran actualidad ${ }^{4}$. Las ideas de Nikolai Karéev, eminente historiador, especialista en la historia moderna de Francia y de Europa en general, gozaron todavía de más popularidad. A ello la ciencia histórica rusa debe el término muy común durante un siglo: soslovnopredstavitel'naya monarkhiya («monarquía estamental representativa»). En el libro de Piskorski este concepto no aparece, mientras que soslovno-predstavitel'noe

3. Pero los profesores universitarios que se dedican a la historia de Europa Occidental de los siglos XVI y XVII, no tienen prisa en cambiar el Departamento de Historia Medieval por el de Historia Moderna. Su decisión es muy lógica: en las facultades de historia de las universidades rusas el período que transcurre desde mediados del siglo Xvir hasta nuestros días se enseña en un mismo departamento de Historia Moderna y Contemporánea. Para los conocedores de Martín Lutero o de la Guerra de los Treinta Años es más cómodo trabajar junto con los especialistas en las Cruzadas o en la Guerra de los Cien Años que con los historiadores que estudian los partidos políticos de finales del siglo XIX o la Segunda Guerra Mundial.

4. PisKorsKi, W. K.: Kastil'skie kortesy v perekhodnuyu epokbu ot srednikb vekov k novomu vremeni (1188-1520). Kiev, 1897 (la traducción española salió a la luz en 1930 y fue reeditada en 1977: Piskorski, W. K.: Las Cortes de Castilla en el período de tránsito de la Edad Media a la Moderna: 1188-1520. Barcelona, 1977). Sobre Piskorski y, en general, sobre la visión de la historia de la España medieval por los hispanistas rusos, véase más detalladamente: Vedyushkin, V.: «La España de los historiadores rusos (Segunda mitad del siglo XIX - comienzos del siglo xx)», Eslavística Complutense, 14, 2014, pp. 107-114. 
VLADISLAV DMÍTRIEVICH NAZÁROV, PÁVEL YÚRIEVICH OUVÁROVY VLADÍMIR ALEKSÁNDROVICH VÉDYUSHKIN LAS INSTITUCIONES RUSAS DE REPRESENTACIÓN DURANTE LOS SIGLOS XVI Y XVII EN EL CONTEXTO EUROPEO: UNA PERSPECTIVA HISTORIOGRÁFICA

sobranie («asamblea estamental representativa») figura solamente una vez ${ }^{5}$. Hay que indicar que la noción de soslovie (estamento) se constituye en Rusia por iniciativa del poder estatal y lo hace bastante tarde, concretamente en el siglo XVIII. Los sosloviya se definen en este tiempo como los grupos hereditarios que poseen ciertos derechos sociales y privilegios. Según Svod zakonov Rossiyskoi imperii («La recopilación de leyes del Imperio ruso»), toda la población de Rusia consistía en cuatro principales «géneros de hombres»: los nobles, los eclesiásticos, los «vecinos ciudadanos» y los «vecinos campesinos». En el Congreso de 2013 Mikhail Boytsov llamó la atención de los participantes afirmando que esta noción fue para Karéev una razón para insistir que «en la sociedad medieval de Occidente, desde la época feudal, distinguimos cuatro estados: los nobles, los eclesiásticos, los ciudadanos y los campesinos, y estos cuatro estados permanecieron inamovibles durante toda la Edad Moderna» ${ }^{6}$.

El tránsito de Rusia a la monarquía constitucional (la primera Duma Estatal (Gosudárstvennaya Duma) comenzó a funcionar en el año 1906) fue, desde este punto de vista, la recuperación de lo perdido, la reiteración de la experiencia europea de los siglos XVI y XVII. Las ideas introducidas por Karéev se arraigaron entre los historiadores soviéticos que estudiaban la historia de los países de Europa occidental y caracterizaban la monarquía estamental representativa (o, según la propuesta de Evguenia Gutnova, autora de una obra fundamental sobre el surgimiento del parlamento inglés, la monarquía feudal con la representación de los estamentos ${ }^{7}$ ), como una etapa determinada de la transformación del estado feudal del período de desmembración feudal a la monarquía absolutista. Los investigadores especialistas en la historia de Europa occidental convenían en su mayoría en este punto de vista; los rusistas siguieron sus huellas. Unos y otros estaban convencidos de que la representación de los estamentos es un concepto muy común en las historiografías occidentales. Por esta razón, hasta años recientes, los países de Europa occidental y después el Estado ruso durante el período de

5. Véase el selecto y sutil análisis terminológico de la noción «representación estamental» en la historiografía rusa: Boytsov, M. A.: «Soslovno-predstavitel'naya monarkhiya: oshibka v perevode?», Srednie veka, 75:3-4, 2014, pp. 66-78. Nos apoyamos aquí en sus observaciones y conclusiones.

6. KARÉEv, N. I.: Pomest'e-gosudarstvo i soslovnaya monarkhiya srednikh vekov: ocherk razvitiya sotsial'nogo stroya y politicheskikh uchrezhdeniy v Zapadnoi Evrope v srednie veka. $3^{\mathrm{a}} \mathrm{ed}$. San Petersburgo, 1913, p. 177.

7. GutNova, E. V.: Vozniknovenie angliyskogo Parlamenta: iz istorii angliyskogo obshchestva $i$ gosudarstva XIII veka. [Moscú], 1960, p. 38. El mismo término técnico fue utilizado en los trabajos de N. A. Khachaturián, conocida especialista en la historia de los Estados Generales y, en general, en la historia de la Francia medieval: Khachaturián, N. A.: Vozniknovenie General'nykh Schtatov vo Frantsii. Moscú, 1976; KHACHATURIÁN, N. A.: Soslovnaya monarkhiya vo Frantsii XIII-XV vv. Moscú, 1989. 
VLADISLAV DMÍTRIEVICH NAZÁROV, PÁVEL YÚRIEVICH OUVÁROV Y VLADÍMIR ALEKSÁNDROVICH VÉDYUSHKIN LAS INSTITUCIONES RUSAS DE REPRESENTACIÓN DURANTE LOS SIGLOS XVI Y XVII EN EL CONTEXTO EUROPEO: UNA PERSPECTIVA HISTORIOGRÁFICA

tránsito de la Edad Media a la Moderna se concebían como monarquías basadas en la representación de todos los estamentos, que periódicamente se reunían para las consultas y las negociaciones con el gobierno central, defendiendo sus intereses, al tiempo que participaban en el gobierno del país.

La monarquía absoluta llegaría cuando esta desplazase a la representación de los estamentos, cuando «el poder real se hubiera reforzado hasta tal punto que podía someter a su dominio a la aristocracia feudal y gobernar el país con la ayuda del aparato burocrático» y «las instituciones de representación de los estamentos, creados anteriormente, perdieron su importancia o dejaron de funcionar» ${ }^{8}$.

En la Rusia post-soviética, a excepción de los trabajos de N. A. Khachaturián (que continuaba sus investigaciones anteriores ${ }^{9}$ ), faltaban tentativas de generalización teórica o, por lo menos, de enfoques integrales y estudios comparativos del fenómeno de la representación durante la época medieval y de la Alta Edad Moderna. La atención de los investigadores rusos se orientó hacia otros aspectos de la cultura política occidental. Se investigaban el papel de la Corte Real ${ }^{10}$, las ceremonias públicas y los rituales del poder ${ }^{11}$, las estrategias retóricas de las instituciones políticas que pretendían atribuirse el papel de representantes del «pueblo» y del «país» ${ }^{12}$ o el uso de las instituciones de representación por algunos políticos o clanes nobiliarios ${ }^{13}$.

Pero hasta ahora el análisis histórico no ha superado la interpretación del concepto anterior de la representación de los estamentos como una etapa definida del régimen político, seguida por la etapa absolutista. La explicación es simple: términos

8. Kolesnitsky, N. F. (coord.): Istoriya srednikh vekov. Moscú, 1980, pp. 387-388.

9. Khachaturián, N. A.: Vlast' i obshchestvo v Zapadnoy Evrope v Srednie Veka. Moscú, 2008.

10. Khachaturián, N. A. (coord.): Dvor monarkha v srednevekovoy Evrope: yavlenie, model', sreda. Moskva, SPb., 2001; KHACHATURIÁn, N. A. (coord.): Korolevski dvor v politicheskoy kul'ture srednevekovoy Evropy. Teoriya. Simvolika. Tseremonial. Moscú, 2004; SHIsHKIN V. V. Korolevski dvor I politicheskaya bor'ba vo Frantsii XVI-XVII vv. San Petersburgo, 2004; Fiódorov, S. E. (coord.): Korolevski dvor v Anglii XV-XVII vekov. San Petersburgo, 2011; VeDYushKIN, V. A.: «Dvor Filippa III glazami sovremennika», Novy filologuicheski vestnik, 2:29, 2014, pp. 129-139.

11. Khachaturián, N. A. (coord.): Sviaschennoe telo korolia. Ritualy i morfologuiya vlasti. Moscú, 2006; BoyTsov, M. A.: Velichie i smirenie, Ocherki politicheskogo simvolisma v srednevekovoy Evrope. Moscú, 2009.

12. Véase, por ejemplo, los numerosos artículos de O. V. Dmítrieva sobre el Parlamento y la cultura política en Inglaterra desde mediados del siglo Xvi hasta comienzos del xviI, en virtud de los cuales la autora preparó un estudio monográfico fundamental; TsaTúrova, S. K.: Ofitsery vlasti: Parizhski parlament v pervoy treti XV v. Moscú, 2002. TsatúRova, S. K.: Formirovanie instituta gosudarstvennoi sluzhby vo Frantsii XIII-XV vekov. Moscú, 2012; Ouvárov, P. Yu.: «Parizhski universitet I mestnye interesy (konets XIV - pervaya polovina XV v.», Srednie veka, vol. 54, 1991, pp. 55-71.

13. Véase, por ejemplo: Tsatúrova, S. K.: «Skandal v koridorakh vlasti vo Frantsii XIv v.», en VÁriash O. I., (coord.): Pravo v srednevekovom mire. Moscú, 1996 c. 221-269. 
VLADISLAV DMÍTRIEVICH NAZÁROV, PÁVEL YÚRIEVICH OUVÁROVY VLADÍMIR ALEKSÁNDROVICH VÉDYUSHKIN LAS INSTITUCIONES RUSAS DE REPRESENTACIÓN DURANTE LOS SIGLOS XVI Y XVII EN EL CONTEXTO EUROPEO: UNA PERSPECTIVA HISTORIOGRÁFICA

tan comunes tienen poco valor heurístico para los estudios concretos y detallados, y para las necesidades de la enseñanza el modelo anterior resultaba bastante cómodo.

El hecho de que la realidad reflejada en las fuentes primarias de las distintas regiones de Europa no correspondiera a este esquema con bastante frecuencia, se explicaba por el carácter específico histórico de cada país. Si hablamos sobre el caso ruso, hay que añadir el estado poco satisfactorio de las fuentes primarias.

Realmente, la documentación para la historia de Rusia de la Baja Edad Media y Alta Edad Moderna, comparándola con los países de Europa occidental, se ha conservado mucho peor. Una parte muy importante de los archivos rusos ha perecido en desastrosos incendios que tan frecuentemente asolaban las ciudades rusas debido a la difusión tan amplia de la construcción en madera y por otras razones. Por este motivo, nos encontramos con grandes pérdidas en la documentación del gobierno central para los siglos XVI y XVII, pero la situación con los archivos privados, personales o familiares es, todavía, mucho peor; para la Edad Moderna los rusistas no tienen a su disposición nada comparable con el Archivo de la Nobleza en Toledo (aunque en parte esta laguna se subsana gracias al buen estado de conservación de algunos archivos monásticos).

En el caso de Rusia es muy importante el hecho de que las relaciones de los extranjeros contienen información muy detallada sobre algunas realidades políticas rusas. Describen la vida rusa, y aunque a veces comprenden bastante bien todos los rasgos específicos del Estado moscovita, en algunas ocasiones no tienen términos adecuados para describirlos de manera comprensible ante sus lectores, por eso utilizan términos como los Estados [Generales], el canciller o la Casa del Consejo. Tal fue, por ejemplo, el caso del capitán francés Jaques Margeret, autor de la descripción de Rusia dedicada al rey Enrique IV de Francia ${ }^{14}$.

La comprensión del término técnico y la noción de monarquía estamental representativa (representación de los estamentos) es una construcción exclusivamente rusa y no tiene análogos directos en las lenguas de Europa occidental, habiendo llegado muy tarde. Aunque el carácter artificial de esta construcción parece evidente (por ejemplo, en Wikipedia el artículo absolutismo está presente en 70 lenguas, y el término técnico la monarquía estamental representativa solamente en ruso y ucraniano), los historiadores rusos estaban convencidos de que el término técnico ruso es un calco del término técnico europeo.

Este hecho fue subrayado por Mikhaíl Boytsov en su ponencia del Congreso al que venimos refiriéndonos ${ }^{15}$. Boytsov insistió que en Europa Occidental, y ante

14. Marjeret, J.: Sostoyanie Rossiyskoy imperii. J. Marjeret v dokumentakh i issledovaniyakh (Teksty, kommentarii, stat'i). Moscú, 2007, pp. 124-126.

15. BoyTsov, M. A.: «Soslovno-predstavitel'naya monarkhiya: oshibka v perevode?», Srednie veka, 75:3-4, 2014, pp. 66-78. 
VLADISLAV DMÍTRIEVICH NAZÁROV, PÁVEL YÚRIEVICH OUVÁROV Y VLADÍMIR ALEKSÁNDROVICH VÉDYUSHKIN LAS INSTITUCIONES RUSAS DE REPRESENTACIÓN DURANTE LOS SIGLOS XVI Y XVII EN EL CONTEXTO EUROPEO: UNA PERSPECTIVA HISTORIOGRÁFICA

todo en Alemania, no se trataba sobre la representación de los intereses de unos u otros estamentos. Estos últimos, si existían, lo hacían ante todo como fruto de la especulación de los doctos letrados y no como una realidad empírica. Para aquel tiempo fue muy importante mostrar la unión simbólica del país frente al soberano, y los representantes de los ordines, territorios o instituciones se reunían, ante todo, con este motivo. Es significativo que muchos participantes del Congreso, no siempre partidarios de la opinión de Boytsov, han mostrado en sus ponencias que de facto se trataba de una representación simbólica más que real. Subrayamos que no pocas veces surgían referencias sobre casos de representación de los territorios, las ciudades y los grupos sociales, inexistentes en la realidad.

Para Rusia, el problema de la representación local en la capital se veía perjudicada por las grandes distancias que separaban los diversos territorios y ciudades que componían la vasta extensión geográfica del Estado; por ejemplo, la distancia en línea recta entre Moscú y Astracán es casi de $1300 \mathrm{~km}$. Y aunque eran superadas tales distancias, estas dependían mucho de la estación del año en que los diputados se desplazaban hasta Moscú; con bastante frecuencia esta situación era tomada en consideración para fijar la fecha de apertura de la Asamblea Nacional. Con tales condiciones, la representación territorial plena en las asambleas de la tierra fue de facto imposible incluso en los períodos más tranquilos, sin hablar del Período de los Tumultos. Pero hay que tener en cuenta que los representantes de los altos grupos de la nobleza provincial de servicio permanecían regularmente en Moscú y podían ejercer las funciones de representación en caso necesario. La misma práctica existía entre los representantes de los mercaderes y artesanos.

Este período fue especialmente difícil para la historia rusa, repleto de giros inesperados en el estilo de la estética barroca. No casualmente los personajes de los impostores rusos alzados de improviso a las cimas del poder y, también de improviso, precipitados, han atraído la atención de sus contemporáneos europeos y han inspirado a varios dramaturgos, incluyendo a Lope de Vega y Calderón ${ }^{16}$.

La importancia del Período de los Tumultos en Rusia para el contexto que aquí estudiamos, se explica por el hecho de que el florecimiento de las instituciones representativas comienza precisamente en este tiempo. Los intentos de mostrar la actividad regular de los órganos representativos en una época más temprana se explican por un intento de hacer arraigar en el pasado el surgimiento de las instituciones representativas (posiblemente para reducir el atraso de Rusia respecto a Occidente, en este sentido). Aunque esporádicamente el gobierno central pudo consultar a los representantes de los grupos sociales (por ejemplo, en la Asamblea

16. Es muy curioso que algunos de ellos encontraban paralelismos entre los acontecimientos de Rusia y los de la Península Ibérica. Por ejemplo, Antonio Possevino, primer jesuita que visitó Rusia, comparó a Demetrio I «el Falso» con los «Falsos» Sebastianes de Portugal. 
VLADISLAV DMÍTRIEVICH NAZÁROV, PÁVEL YÚRIEVICH OUVÁROVY VLADÍMIR ALEKSÁNDROVICH VÉDYUSHKIN LAS INSTITUCIONES RUSAS DE REPRESENTACIÓN DURANTE LOS SIGLOS XVI Y XVII EN EL CONTEXTO EUROPEO: UNA PERSPECTIVA HISTORIOGRÁFICA

de febrero de 1549 -el Sobor del apaciguamiento- o en la Asamblea de 1566), hasta la extinción de la Dinastía Ruríkida (que gobernaba las tierras rusas desde el siglo Ix hasta el año 1598) no surge la necesidad de buscar legitimación adicional.

Desde el reinado de Borís Godunov (1598-1605) las apelaciones a la voluntad de «toda la tierra» se hacen más frecuentes. Por lo demás, algunos historiadores (en particular, M. M. Krom y V. D. Nazárov) prestan atención al uso del término «consejo de la tierra» antes del reinado de Borís Godunov, con alguna contraposición entre «lo del zar» $\mathrm{y}$ «lo de la tierra». En este contexto tiene gran importancia la división del territorio de Rusia por el zar Iván el Terrible en dos partes: Opríchnina, las tierras personales del zar (donde él poseía poder ilimitado), y Zémschina, que conservaba el orden social y la administración anteriores (constituidos a mediados del siglo xvI). A propósito, no es casual que algunos contemporáneos de la Smuta supusieran que su origen radicaba en la división de las tierras rusas efectuada por Iván IV. Sea como fuere, en condiciones de crisis aguda de legitimidad y de parálisis de las estructuras del poder central durante el Período de los Tumultos, la población de muchas regiones se veía obligada a actuar por sí misma. En sus inicios, esta situación afectaba únicamente a las tierras del sudoeste, pero más tarde se extendió por otras tierras, especialmente en tiempos de la Primera y Segunda Milicia Popular (1611-1612). Al mismo tiempo, los poderes que se encontraban en el Kremlin (el zar Vasily Shuiski (Basilio IV), los «siete boyardos», los representantes del príncipe Ladislao, hijo de Segismundo III de Polonia) publicaban sus disposiciones referiéndose a «las resoluciones de toda la tierra» (aunque evidentemente era ficción).

Como muestran los estudios recientes, la elección de Mikhaíl Romanov, en febrero de 1613, apenas parecía un acto de voluntad legítima de todos los grupos sociales y de todos los territorios del país. Se apeló a muchas candidaturas, entre otras, la del príncipe Carlos Felipe, como alternativa posible al pretendiente polaco. Pero los cosacos, el elemento más activo e inquieto de la Smuta, consiguieron, por medio de una serie de circunstancias coyunturales, la afirmación de la candidatura, de ningún modo indiscutible, de Mikhaíl Romanov. Es remarcable que durante algún tiempo el nuevo zar no se consideraba a sí mismo como tal. Por ejemplo, el autor del memorial enviado al rey Jacobo I de Inglaterra llamó a Mikhaíl Romanov «rey de cosacos», señalándole como personaje no respetado, y proponía al rey de Inglaterra organizar la invasión de Rusia para impedir a los «papistas» -los polacos católicos- instalarse en el poder. El autor del memorial (actualmente los historiadores saben que fue Jaques Margeret, ya mencionado por nosotros) aseveró que los rusos soñaban con ver a un soberano extranjero en el trono ruso, quien, además, establecería por fin en el país la paz y el orden ${ }^{17}$. Pero en contra de

17. MarJeret, J.: Sostoyanie Rossiyskoy imperii. J. Marjeret v dokumentakh i issledovaniyakh (Teksty, kommentarii, stat'i). Moscú, 2007, pp. 390-395. 
VLADISLAV DMÍTRIEVICH NAZÁROV, PÁVEL YÚRIEVICH OUVÁROV Y VLADÍMIR ALEKSÁNDROVICH VÉDYUSHKIN LAS INSTITUCIONES RUSAS DE REPRESENTACIÓN DURANTE LOS SIGLOS XVI Y XVII EN EL CONTEXTO EUROPEO: UNA PERSPECTIVA HISTORIOGRÁFICA

los pronósticos, Mikhaíl Romanov consiguió asentarse en el poder, aunque todo su reinado, así como el de su hijo Alekséi Mijáilovich, estuvo acompañado por las convocatorias de Zemskie Sobory y por las apelaciones a su autoridad (véase, más detalladamente, el artículo de Tatiana Lápteva en este informe).

La primera mitad del siglo xvir es conocida como el «siglo de oro» de las instituciones representativas en Rusia. La representación funcionaba efectivamente a nivel local (lo que, por lo demás, es igualmente característico para el período anterior), pero a nivel estatal también. La aprobación del Sobor se necesitaba para las acciones importantes de política exterior (como, por ejemplo, el apoyo para Azov, en aquel tiempo en manos de los cosacos, en 1642 o la reunificación de Ucrania con Rusia en 1653), pero igualmente para disolver los asuntos tocantes a los intereses de los grupos sociales privilegiados, tales como las corporaciones de nobleza, por ejemplo, o el aumento del plazo de la búsqueda de los campesinos prófugos (urochnye leta).

Para comprender mejor la situación historiográfica actual en los estudios rusos sobre la representación y participación de los distintos grupos sociales en el gobierno es necesario caracterizar los estudios de los rusistas sobre el tema. La historiografía rusa y soviética de las instituciones representativas en Rusia durante los siglos XVI y xviI es muy extensa y polifacética. Los resultados y las peculiaridades de su desarrollo han determinado los temas de las ponencias de los rusistas en el Congreso de 2013. Los participantes tuvieron una causa concreta e importante para la actividad que conmemoraban en común: el cuarto centenario del Zemski Sobor más representativo en la historia rusa. Pero los que estudiaban este tema en el siglo XIX tuvieron otro motivo social de gran peso: separar la representación de la sociedad y las instituciones e ideas de la monarquía autócrata y contraponer uno a otro. Para el decembrista Nikita Muraviov las asambleas estatales (así denomina los Zemskie Sobory) durante el reinado de los tres primeros zares de la dinastía de los Romanov, en sus decisiones sobre los asuntos legislativos e internacionales, eran «la base razonable» que, en ciertas condiciones, «podía convertirse en parlamento». Esta idea, con unas u otras variaciones, fue casi central en la polémica entre los eslavófilos (slavianofily) y los occidentalistas (zapadniki) por la oposición o reconsideración de la tríada oficial bajo el zar Nikolai I: «samoderzhavie, pravoslavie, narodnost» (autocracia, ortodoxia, espíritu nacional). El mismo nacimiento de la noción "Zemski Sobor» (las fuentes de los siglos Xvi y Xvir no la conocen) se debe a estas disputas. Por primera vez esta noción fue utilizada quizás por Konstantín Aksákov en su polémica contra Serguei Soloviov. Según el eslavófilo Aksákov, el primer zar ruso, Iván el Terrible, convoca el primer Zemski Sobor, y en esta asamblea «se encuentran la tierra y el estado», concertando una «alianza libre», según la fórmula: «la fuerza del poder, al estado; la fuerza de la opinión, a 
VLADISLAV DMÍTRIEVICH NAZÁROV, PÁVEL YÚRIEVICH OUVÁROVY VLADÍMIR ALEKSÁNDROVICH VÉDYUSHKIN LAS INSTITUCIONES RUSAS DE REPRESENTACIÓN DURANTE LOS SIGLOS XVI Y XVII EN EL CONTEXTO EUROPEO: UNA PERSPECTIVA HISTORIOGRÁFICA

la tierra» ${ }^{18}$. Para Serguei Soloviov, historiador profesional, lo más importante no es la teoría, sino los textos de las fuentes primarias (se debe notar que en tiempos de Soloviov se conocían muy pocas); analizándolas, Soloviov subraya que «toda la tierra» no fue representada en el Sobor de 1566 y que el principio electivo en la representación local de los Sobory surge solamente en los años de la Smuta. La polémica en torno a los tres pequeños fragmentos sobre los Sobory en tres volúmenes de su obra clásica La bistoria de Rusia desde los tiempos más remotos (Istoriya Rossii s drevnéishikh vremión) se prolongó durante 5 años (1856-1860). Dos hechos son relevantes: primero, la disputa entre hombres de distintas profesiones; segundo, el gran interés público (la polémica se desarrollaba en Rússkaya beseda, periódico que no era una publicación sobre ciencia histórica). Discusiones semejantes se repitieron aún con bastante frecuencia.

Junto con estas tendencias en los estudios sobre los Zemskie Sobory y en las valoraciones de su papel (que no siempre fueron resultado de los primeros), en la década de 1860 acaba siendo habitual mencionar los Sobory no solamente en los cursos generales de historia de Rusia, sino también en los cursos universitarios de historia del derecho ruso. Esto influyó tanto en el planteamiento de los problemas como en la metodología a la hora de tomar decisiones. La tradición eslavófila fue continuada en los años sesenta del siglo xIx por I. D. Beliáev (como historiador, concretó y desarrolló las ideas de Aksákov, que no fue historiador) y reformada por A. P. Shchápov. Sus trabajos constituyen «la corriente democrática» con interés especial en el carácter electivo de los Zemskie Sobory y en las instituciones representativas territoriales.

Una de las primeras tentativas de análisis basado en criterios histórico-jurídicos (B. N. Chicherin) mostró, de un lado, la necesidad de métodos histórico-comparativos, y, de otro, su complejidad y ambigüedad ${ }^{19}$. Para el uso de estos métodos se necesitaba una clasificación más rígida de los Sobory según un complejo acervo de características. Los resultados no infundían optimismo. Según Chicherin, dado el desarrollo enorme del poder autocrático y el estado de servidumbre de la mayor parte de la población, los Zemskie Sobory no tenían derechos políticos, no intervenían en los asuntos del gobierno, no han dejado ni una señal de las discusiones en su interior y tuvieron un papel meramente consultivo. En consecuencia, su importancia en la vida de la sociedad fue mucho menor que en los países de Europa occidental. Claro que se trata de las apreciaciones rígidas de un jurista del siglo XIX, limitado por la concepción de su tiempo y de su profesión y por eso no siempre capaz de comprender los procesos de aparición y desarrollo de los Sobory. Pero al mismo tiempo estos conceptos han estimulado el desarrollo

18. Aksákov, K. S.: Polnoe sobranie sochineniy, t. 1. Moscú, 1861, p. 150.

19. Chicherin, B. N.: O narodnom predstavitel'stve. Moscú, 1866. 
VLADISLAV DMÍTRIEVICH NAZÁROV, PÁVEL YÚRIEVICH OUVÁROV Y VLADÍMIR ALEKSÁNDROVICH VÉDYUSHKIN LAS INSTITUCIONES RUSAS DE REPRESENTACIÓN DURANTE LOS SIGLOS XVI Y XVII EN EL CONTEXTO EUROPEO: UNA PERSPECTIVA HISTORIOGRÁFICA

de métodos de análisis más rigurosos y, lo más importante, la búsqueda y edición de nuevas fuentes primarias.

La década de 1880 estuvo marcada por una serie de publicaciones de documentos realizadas por I. I. Zhdánov, A. I. Zertsálov, S. F. Platónov y, ante todo, V. N. Latkin. Este último fue también el autor de un libro de carácter general sobre los zemskie sobory, quizá el primero. Un poco antes, V. I. Sergueévich publicó un ensayo general de su historia en Sbórnik gosudárstvennyb znaniy (más tarde reeditada varias veces en sus Léktsii i isslédovaniya po drévnemu rússkomu pravu («Lecciones y estudios sobre el derecho ruso antiguo») ${ }^{20}$. Si añadimos los estudios de Vasili Kliuchevski, los cursos de historia del derecho ruso de N. P. Zagoskin y de M. F. Vladímirski-Budánov ${ }^{21}$, tenemos el abanico completo de los estudios más importantes y de las tendencias principales en la historiografía de las instituciones representativas para estos años. En lo que toca a las fuentes primarias tenemos en esta época la primera búsqueda de la documentación del secretariado de los prikazy (los órganos del gobierno central de Rusia durante los siglos XVI y XVII). Los métodos de análisis consisten en la reconstrucción escrupulosa de las biografías de los participantes en los Sobory en los casos en los que se conocen los nombres. De esta manera Kliuchevski estudiaba los Sobory de 1566 y de 1598. La clasificación de los Sobory según este conjunto de elementos (aunque no coincidían en distintos historiadores) ha permitido caracterizar satisfactoriamente la historia de los Sobory como un proceso (V. N. Latkin,V. I. Sergueévich) y comparar los Sobory con las instituciones representativas de Europa con más éxito. Al igual que en el período anterior, esta nueva etapa presenta dos posiciones opuestas. Para Kliuchevski y Zagoskin los Zemskie Sobory «encarnan un tipo especial de representación popular, que se distingue de las asambleas representativas occidentales», constituyendo un fenómeno exclusivamente ruso. Las conclusiones de Latkin y Sergueévich son muy distintas. Ambos reconocen la proximidad de las correspondientes instituciones en Rusia y en los países europeos ${ }^{22}$ conforme $^{2}$ algunas características: el personal de las asambleas representativas, el orden de la formación y de las elecciones, el ámbito de competencia, la incertidumbre de los

20. Latkin, V. N.: Materialy dlia istorii zemskikh soborov XVII stoletiya. San Petersburgo, 1884; LaTKIN, V. N.: Zemskie sobory Drevney Rusi, ikb istoriya I organizatsiya sravnitel'no s zapadnoevropeyskimi predstavitel'nymi uchrezhdeniyami. San Petersburgo, 1885; SERGEevich, V. I.: «Zemskie sobory v Moskovskom gosudarstve», en Bezobrazov, V. P. (coord.): Sbornik gosudarstvennykh znaniy, t. 2. San Petersburgo, 1875.

21. Kluchevsky, V. O.: «Sostav predstavitelstva na Zemskikh soborakh Drevney Rusi (posviashchaetsia B. N. Chicherinu)», en Kluchevsky, V. O.: Sochineniya v devjati tomakh, t. VIII. Moscú, 1990, pp. 227-334 (1 $1^{\text {a }}$ ed. en 1890-1892); ZAGoskin, N. P.: Istoriya prava Moskovskogo gosudarstva, t. 1. Kazán, 1877; VladimirskiY-Budanov M. F.: Obzor istorii russkogo prava. Kiev, 1886.

22. Latkin realizó su comparación con seis países europeos: Inglaterra, Francia, España, Alemania, Holanda y Suecia. 
VLADISLAV DMÍTRIEVICH NAZÁROV, PÁVEL YÚRIEVICH OUVÁROVY VLADÍMIR ALEKSÁNDROVICH VÉDYUSHKIN LAS INSTITUCIONES RUSAS DE REPRESENTACIÓN DURANTE LOS SIGLOS XVI Y XVII EN EL CONTEXTO EUROPEO: UNA PERSPECTIVA HISTORIOGRÁFICA

plazos de convocatoria, etc. Pero, si Latkin ve casi «afinidad» de estas instituciones entre Rusia y Occidente, Sergueévich ve en los Sobory «el estado embrionario» respecto a los análogos europeos.

El libro de Latkin dio origen a una animada polémica. Uno de los participantes fue N. I. Karéev. Su concepción de los límites y de los objetivos del uso de los métodos histórico-comparativos se distingue en muchos aspectos respecto de la concepción de Latkin. Pero es más importante otra cuestión: durante la polémica de 1886 se planteó la idea de la conexión entre la división de períodos con el cambio de las formas de la sociedad y del estado. En Europa, la monarquía estamental con sus asambleas representativas cambió el feudalismo con su fraccionamiento feudal; y en Rusia, según los conceptos de finales del siglo xix, el feudalismo era inexistente, lo que determinó la originalidad exclusiva de los Zemskie Sobory.

La nueva ola de investigaciones y publicaciones de fuentes primarias sobre el tema apareció entre los años 1905-1917. Dos factores principales determinaron el incremento evidente del interés público y científico respecto a los Zemskie Sobory. De un lado, los primeros pasos de transformación de la monarquía autocrática a una monarquía constitucional durante la Revolución de 1905-1907. De otro, el tercer centenario de la dinastía de los Romanov. En primer lugar, se publicaron más de 10 volúmenes de ediciones de fuentes primarias, en su mayor parte referidas, de manera directa o indirecta, a la historia de los Zemskie Sobory de la época. A esto hay que añadir no pocas ediciones muy valiosas de las actas relativas a los Sobory de los años treina y cuarenta del siglo xviI (incluyendo las actas locales). La historiografía soviética nunca llegó a conocer la actividad tan intensa que se reflejaba en las publicaciones de las fuentes primarias, conservando la mayoría una asombrosa actualidad que ha pervivido hasta nuestros días. El segundo rasgo importante es una ampliación de la problemática de investigación. Nunca antes se había analizado tan sistemáticamente la dilatada diversidad de variantes y formas de actividad de los Sobory del primer cuarto del siglo xviI, como en los estudios monográficos y significativos artículos de S. F. Platónov, P. G. Lubomírover ${ }^{23}$ A. I. Zaozersky, E. D. Stashevsky, Yu. V. Got'e y un largo etc. Otra evidente particularidad es el incremento del interés en los archivos extranjeros (polacos, suecos, neerlandeses, daneses) donde se conservan las fuentes primarias para la historia de Rusia, sobre todo fuentes documentales con una valiosa información sobre algunos Sobory.

23. Platonov, S. F.: Ocherki po istorii Smuty v Moskovskom gosudarstve XVI-XVII vekov. San Petersburgo, 1899; Platonov, S. F.: «K istorii moskovskikh zemskikh soborov», Zhurnal dlia vsekh, 1905, n. ${ }^{\circ}$; Liuвоміrov P. G.: Ocherki istorii nizhegorodskogo opolcheniya 1611-1613 gg. Petrogrado, 1917. 
VLADISLAV DMÍTRIEVICH NAZÁROV, PÁVEL YÚRIEVICH OUVÁROV Y VLADÍMIR ALEKSÁNDROVICH VÉDYUSHKIN LAS INSTITUCIONES RUSAS DE REPRESENTACIÓN DURANTE LOS SIGLOS XVI Y XVII EN EL CONTEXTO EUROPEO: UNA PERSPECTIVA HISTORIOGRÁFICA

Los estudios de N. P. Pávlov-Silvansky ${ }^{24}$ y F. V. Taranovsky son muy característicos para este período. Ellos han aplicado a la historia de Rusia el sistema terminológico y la periodización utilizados por medievalistas y modernistas rusos respecto a los países occidentales. Para Pávlov-Silvansky, los Zemskie Sobory son semejantes a las asambleas representativas de Francia, España, Alemania, Inglaterra, Suecia, etc., porque «el régimen estatal del período Moscovita de los siglos xvi y XVII se desarrolló, así como en Occidente, dentro del régimen feudal». Respectivamente, «el Estado Moscovita con sus Zemskie Sobory fue un estado estamental, así como los estados estamentales occidentales» ${ }^{25}$. Aquí vemos, de un lado, el cambio en la periodización tradicional (normalmente, la antigua historia rusa se dividía en el período de los udeli -heredades feudales que recibía cada hermano a la muerte del padre, correspondiente a la «desmembración feudal» occidental-, el «reino del Zar»-en ruso tsarstvo- de Moscovia e Imperio de Pedro el Grande); de otro lado, el diálogo original con el concepto de Karéev (y su famosa noción de la «monarquía estamental-representativa»). La proximidad con Karéev resultó no solamente conceptual, sino también cronológica: el libro de Karéev salió a la luz en 1906 y el de Pávlov-Silvansky apenas un año más tarde ${ }^{26}$.

Los estudios de los Sobory de los años treinta y, ante todo, de los años cuarenta del siglo xviI conservaban en estos años su actualidad y fueron muy productivos. Además de los aspectos ya tradicionales sobre su funcionamiento (como el orden del día, el sistema de entrega de los pareceres, la composición de los Sobory y los plazos de sus sesiones), se estudiaban con más cuidado las prácticas de las elecciones de los diputados en las regiones del sur, el papel de las autoridades y administraciones locales en las mismas y las opiniones de la población de la región correspondiente. En los mismos años se publicó el libro monográfico fundamental de M. M. Bogoslovsky dedicado a la historia de la autonomía del zemstvo (en este caso la autonomía de la administración local y provincial) en las regiones nórdicas y nororientales de la parte europea de Rusia ${ }^{27}$. Igualmente, fue lógica la aparición de los primeros estudios historiográficos sobre los Sobory (S. L. Avaliani, I. A. Stratonov ${ }^{28}$ ), las publicaciones de las fuentes primarias sobre los Sobory con fines

24. Pávlov-Silvansky, N. P.: Feodalizm v Drevney Rusi. San Petersburgo, 1907.

25. Pávlov-Silvansky, op. cit., pp. 131-140.

26. Karéev, N. I.: Pomest'e-gosudarstvo i soslovnaya monarkhiya srednikh vekov: ocherk razvitiya sotsial'nogo stroya y politicheskikh uchrezhdeniy v Zapadnoi Evrope v srednie veka. San Petersburgo, 1906.

27. Bogoslovski M. M. Zemskoe samoupravlenie na russkom severe v XVII v., t. 1-2, Moscú, 1909-1912.

28. Avaliani, S. A.: Zemskie sobory. Literaturnaya istoria zemskikh soborov. Odessa, Izdanie 2-e, 1916; Stratonov, I. A.: Zametki po istorii zemskikh soborov Moskovskoy Rusi. Kazán, 1912. 
VLADISLAV DMÍTRIEVICH NAZÁROV, PÁVEL YÚRIEVICH OUVÁROVY VLADÍMIR ALEKSÁNDROVICH VÉDYUSHKIN LAS INSTITUCIONES RUSAS DE REPRESENTACIÓN DURANTE LOS SIGLOS XVI Y XVII EN EL CONTEXTO EUROPEO: UNA PERSPECTIVA HISTORIOGRÁFICA

pedagógicos, así universitarios, como para la escuela secundaria (Yu. V. Got'e ${ }^{29}$ ) y ediciones de libros de divulgación.

En los mismos años salieron a la luz los primeros estudios con la concepción marxista de la evolución de los Sobory. Hay que indicar que ni M. N. Pokrovsky, ni N. A. Rozhkov (los historiadores marxistas más conocidos de la época) prestaban mucha atención a este tema porque no suponían que la evolución de la «superestructura política» fuera lo más importante y más interesante en la historia, dedicándole tan solo pequeños capítulos en sus cursos de historia rusa. El establecimiento del poder soviético no influyó mucho en las opiniones de estos historiadores sobre los Zemskie Sobory. Paralelamente, en los años veinte del siglo xx continuaban saliendo a la luz estudios sobre algunos Sobory escritos por los miembros de la Escuela de Platónov en Leningrado y de la «generación joven» de la Escuela de Kluchevsky en Moscú. En los debates de finales de los años veinte $\mathrm{y}$ mediados de los años treinta del siglo xx casi no se tocaban los problemas de historia política de Rusia de los siglos XVI y XVII. La situación cambió a mediados de los años treinta, después del «proceso de los académicos» de 1929-1931 (todos los condenados, conocidos historiadores, pertenecían al ámbito académico o universitario) y en particular después de las represiones contra los historiadores de la Escuela de Pokrovsky. Por entonces se elaboraba y formulaba la teoría de las formaciones socio-económicas, en cuyos límites la formación feudal adquirió su estatus universal, al tiempo que se determinaban las etapas de su desarrollo. Respectivamente, este concepto era sobrepuesto en la periodización de la historia de Rusia y expuesto, ante todo, en los manuales universitarios y de la escuela secundaria, así como en los textos de las obras generales que se comenzaron a preparar en aquel tiempo.

Con la unificación del aparato conceptual, la fórmula de la «monarquía estamental-representativa» adquirió el estatus de axioma. Con todo esto, los matices en el modo de interpretar esta noción permanecían. En las discusiones sobre la periodización de la historia rusa de la época del feudalismo, algunos científicos ligaban el comienzo de la «monarquía estamental-representativa» en Rusia con el tránsito del siglo Xv al XVI (S. V. Yushkov), mientras otros databan este cambio después de 1549 y suponían que los decenios de finales del siglo xv y de la primera mitad del xvi correspondían a la época de la monarquía estamental (A. A. Zimín, S. O. Shmidt). Es importante señalar que la fecha de 1549 no es casual. S. O. Shmidt encontró un nuevo texto de una crónica que ha permitido probar con hechos la existencia del «Sobor de pacificación» de febrero de 1549. La mayoría de los especialistas sobre el tema consideran que el «Sobor de pacificación» fue el primer Zemski Sobor en la historia de Rusia. Los estudios monográficos de los

29. Got’e, Ju. V. (ed.): Akty otnosiashchiesia k istorii zemskikh soborov. Moscú, 1909. 
VLADISLAV DMÍTRIEVICH NAZÁROV, PÁVEL YÚRIEVICH OUVÁROV Y VLADÍMIR ALEKSÁNDROVICH VÉDYUSHKIN LAS INSTITUCIONES RUSAS DE REPRESENTACIÓN DURANTE LOS SIGLOS XVI Y XVII EN EL CONTEXTO EUROPEO: UNA PERSPECTIVA HISTORIOGRÁFICA

años 1950-1970 sobre algunos Sobory conservan un carácter bastante tradicional. Se prestaba especial atención a los Sobory de 1566 y 1598 (A. A. Zimín, S. O. Shmidt $^{30}$, R. G. Skrýnnikov, S. P. Mordóvina). Se iniciaron entonces esfuerzos para exagerar el número de los Sobory (pues las indicaciones de las fuentes primarias no son claras); por ejemplo, por S. O. Shmidt y V. I. Koretsky, pero pocos de ellos fueron aprobados por otros expertos. Los Zemskie Sobory de los años treinta y cuarenta fueron investigados por A. A. Novosel'sky y P. P. Smirnov. Estos autores analizaron el papel público de los Sobory, los pareceres de los diputados representantes de los distintos grupos sociales en los asuntos de política exterior, así como en la preparación, discusión y aprobación del Sobórnoye ulozbéniye (la recopilación de leyes aprobada en el Sobor de 1649) y en la realización posterior de algunas partes de esta recopilación. M. N. Tikhomírov dedicó su estudio al Zemski Sobor de 1650, convocado en relación al levantamiento de Pskov ${ }^{31}$.

Los paralelismos con instituciones similares de Europa Occidental no se establecían en aquella época y se conservaban, en general, los planteamientos tradicionales: se reconocía a grandes rasgos la semejanza (pero no la identidad ni afinidad) de los Zemskie Sobory con las asambleas representativas en los países de Europa Occidental. Aún más, la tesis sobre la afinidad del sistema de gobierno ruso con el sistema social y con las instituciones políticas del Imperio Otomano fue adelantada durante una de las discusiones sobre el absolutismo por M. P. Pavlova-Silvánskaya.

Los libros de N. E. Nósov y L. V. Tcherepnín han jugado un papel clave en la historiografía soviética de los Zemskie Sobory ${ }^{32}$. El libro de Nósov está dedicado a los principios y las prácticas de representación estamental a nivel local, a las particularidades de la realización de la reforma de zemschina a mediados de los años 1550. Es importante indicar que todo esto se estudiaba en relación con el racionamiento estatal del servicio militar de todos los deti boyarskie (el menor de los rangos de la nobleza) provinciales, así como de los miembros de Gosudárev $d v o r$, de sus grupos medios e inferiores, y con su respectivo apoyo material. La variedad de funciones y derechos, el carácter electivo y la representatividad de los distintos grupos de población provincial en estas asambleas, dada su subordinación

30. Shmidt, S. O.: Stanovlenie rossiyskogo samoderzhavstva. Moscú, 1973.

31. Novosel'ski, A. A.: Bor'ba Moskovskogo gosudarstva s tatarami v pervoi polovine XVII veka. Moscú; Leningrado, 1948; Smirnov, P. P.: Posadskie liudi i ikh klassovaya bor'ba do serediny XVII v., t. 1-2. Moscú; Leningrado, 1947, 1948; Tikнomirov, M. N.: «Pskovskoe vosstanie 1650 goda» en Tiкномirov, M. N.: Klassovaya bor'ba v Rossii XVII v. Moscú, 1969, pp. 23-138 (1 ${ }^{\text {a }}$ ed. en 1935); Tiкномirov, M. N.: «Dokumenty Pskovskogo vosstaniya i Zemskogo Sobora 1650 goda» en Tikнomirov, M. N.: Klassovaya bor'ba v Rossii XVII v. Moscú, 1969, pp. 234-332 (1ª ed. en 1958).

32. Nosov, N. E.: Stanovlenie soslovno-predstavitel'nykh uchrezhdeniy v Rossii. Leningrado, 1969; TCherePnin, L. V.: Zemskie sobory Russkogo gosudarstva v XVI-XVII vv. Moscú, 1978. 
VLADISLAV DMÍTRIEVICH NAZÁROV, PÁVEL YÚRIEVICH OUVÁROVY VLADÍMIR ALEKSÁNDROVICH VÉDYUSHKIN LAS INSTITUCIONES RUSAS DE REPRESENTACIÓN DURANTE LOS SIGLOS XVI Y XVII EN EL CONTEXTO EUROPEO: UNA PERSPECTIVA HISTORIOGRÁFICA

directa a las autoridades centrales en Moscú, impulsaron la actividad de estas instituciones representativas.

El libro de L. V. Tcherepnín, publicado a título póstumo, ha realizado un balance de más de 150 años de los estudios de los Zemskie Sobory por los historiadores rusos. Es evidente que este balance fue realizado según el concepto marxista soviético desarrollado al comienzo de los años sesenta del siglo xx. Pero igualmente es una continuación de la tradición investigadora en el trabajo con fuentes primarias de la Escuela de Kluchevsky: Tcherepnín fue discípulo de S. V. Bakhrushin y de A. I. Yákovlev, pertenecientes ambos a la «generación joven» de los discípulos de Kluchevsky. El libro de Tcherepnín es un clásico por su propósito, composición y realización. El autor investiga cronológicamente todos los fenómenos que comprenden los Sobory, según el conjunto de indicios encontrado. Se trata de un análisis sistemático del conjunto de fuentes narrativas, de todas las actas y documentos, así ya conocidos como involucrados por él por primera vez. Con tal planteamiento, la evolución de los Sobory, comenzando con sus raíces arquetípicas (las reuniones de los príncipes, las asambleas del ejército), se divide, de manera habitual, en ocho etapas, cada una de las cuales tuvo sus peculiaridades y su evolución particular. Es muy importante comprender que la historia de casi todos los Sobory está incluida en un contexto social e ideológico muy amplio. El libro concluye con la definición del número de los Zemskie Sobory, estableciéndose su correspondiente clasificación y analizándose los aspectos más importantes: los Sobory y la autocracia, los Sobory y el pueblo, los Sobory y los problemas de ideología, los Sobory y la posición internacional del país.

Las peculiaridades de los estudios sobre los Zemskie Sobory en la historiografía rusa entre los años 1980-2010 estuvieron determinadas así por los cambios políticos, como por los cambios en la propia ciencia histórica. El rechazo y abandono del concepto marxista para el proceso histórico mundial no generó su canje por otro concepto reconocido por todos. En el caso concreto de Rusia durante los siglos XVI y XVII, la situación se complica por la gran variedad de teorías sobre filosofía de la historia acerca de su vía exclusiva (no europea) de desarrollo histórico, aunque los partidarios de tales ideas raramente visitan aquellos «espacios de trabajo» donde el investigador se encuentra con las fuentes primarias y, aprovechando sus capacidades profesionales, reconstruye los hechos históricos, fenómenos y acontecimientos concretos.

Después de Tcherepnín, no se ha publicado ningún libro de carácter general análogo en su concepción a la obra de este historiador. Los investigadores concentran sus esfuerzos en tres direcciones: fuentes primarias, nuevas interpretaciones y especificación de los hechos sobre los Sobory más conocidos e importantes, así como nuevos enfoques para encuadrar nuevas prácticas de Sobory en el contexto social y político (a nivel estatal, de la capital, regional, local). 
VLADISLAV DMÍTRIEVICH NAZÁROV, PÁVEL YÚRIEVICH OUVÁROV Y VLADÍMIR ALEKSÁNDROVICH VÉDYUSHKIN LAS INSTITUCIONES RUSAS DE REPRESENTACIÓN DURANTE LOS SIGLOS XVI Y XVII EN EL CONTEXTO EUROPEO: UNA PERSPECTIVA HISTORIOGRÁFICA

De gran actualidad resultaron las nuevas ediciones de las fuentes más importantes sobre los Zemskie Sobory del siglo xvi y comienzos del xvir: la «Carta de decisiones» (Prigovornaya gramota) del sobor de $1566^{33}$ y la «Decisión» (Prigovor) de 30 de junio de 1611 de la Primera Milicia Popular ${ }^{34}$. Los autores de estas líneas sienten especialmente que no se hayan llevado a cabo proyectos de investigación en el contexto de la ciencia actual, de la Utverzhdionnaya gramota de 1598 (con la aprobación de los derechos de Borís Godunov al trono) y la posterior de 1613 (con la aprobación de los derechos de Mikhaíl Románov), ambas con textos complementarios (aunque la segunda fue muy bien editada por S. V. Belokurov ya en 1906). Se publicaron las fuentes primarias con la correspondiente información, directa o indirecta, sobre los Sobory de 1566 (V. D. Nazarov), de 1580 (B. N. Florya), de 1584 (M. P. Lukichov y V. D. Nazarov), de 1586 (en realidad «presunto» Sobor de 1586, A. P. Pavlov, A. L. Stanislavsky), de 1621 (B. N. Florya) y otros. Asimismo, se han publicado dos fuentes excepcionales sobre el Zemski Sobor de 1613: la «Carta» (gramota) del Sobor enviada a Kazán (V. I. Koretsky, M. P. Lukichov, A. L. Stanislavsky) ${ }^{35} \mathrm{y}$ el «Relato del Zemski Sobor» (Povest' o zemskom sobore) de 1613, único en su género (A. L. Stanislavsky, B. N. Morozov) ${ }^{36}$.

Pero la atención principal se focalizó en la edición de las fuentes documentales de registro y contabilidad procedentes en su mayor parte de los archivos del Razriadny prikaz (cancillería cuya función capital fue la del gobierno militar) y del Pomestny prikaz (responsable de los asuntos relacionados con las tierras prestadas a condición del servicio militar), del Archivo de Estado (Gosudarstvennoe drevlekbranilische), de la Cancillería de Heráldica y de la Oficina de los Reyes de Armas y docenas de otros fondos de archivos centrales y provinciales, así como de las secciones de manuscritos de las bibliotecas y museos. El valor científico de estas publicaciones desde el punto de vista de la historia de los Zemskie Sobory consiste en la formación de una base de datos, adecuada, extensa y de fácil acceso, para el análisis sistemático y la descripción del contexto social y político del funcionamiento de los Zemskie Sobory.

En el libro póstumo de A. L. Stanislavsky se hallan publicadas las listas de los miembros de la Corte del Soberano -Gosudárev Dvor- (que constituyen la fuente

33. Antonov, A. V. (ed.): «Prigovornaya gramota 1566 goda» en Antonov, A. V. (coord.): Russkiy diplomatariy, t. 10. Moscú, 2004, pp. 171-182.

34. Andreev, I. L. y Kozliakov, V. N. (eds.): «Prigovor Pervogo zemskogo opolcheniya (1611 goda, iyunia 30)» en Kozliakov, V. N. (ed.): Smutnoye vremia i zemskie opolcheniya v nachale XvII veka. Riazán, 2011, pp. 297-306.

35. Koretsky, V. I., Lukichev, M. P., Stanislavsky, A. L.: «Dokumenty o natsionalno-osvoboditelnoy borbe v Rossii v 1612-1613 gg.» en Lukichev, M. P.: Boyarskie knigi XVII veka: Trudy po istorii i istochnikovedeniyu. Moscú, 2004, pp. 198-234 (1a ed. en 1989).

36. Morozov, B. N. y Stanislavsky, A. L. (eds.): «Povest' o Zemskom sobore 1613 goda», Voprosy istorii, ${ }^{\circ}$ 5, 1985, pp. 89-96. 
VLADISLAV DMÍTRIEVICH NAZÁROV, PÁVEL YÚRIEVICH OUVÁROVY VLADÍMIR ALEKSÁNDROVICH VÉDYUSHKIN LAS INSTITUCIONES RUSAS DE REPRESENTACIÓN DURANTE LOS SIGLOS XVI Y XVII EN EL CONTEXTO EUROPEO: UNA PERSPECTIVA HISTORIOGRÁFICA

principal para esclarecer los nombres de los participantes de los Zemskie Sobory en el siglo xvI) y el repartimiento del ejército ruso para los años $1577-1604^{37}$. Se publicaron igualmente los cuatro tomos de «Akty sluzhylyh zemlevladel'tsev» (Actas sobre los terratenientes a condición del servicio militar) correspondientes al período comprendido entre el siglo xv y comienzos del $\mathrm{XvII}^{38}$. De especial interés es la publicación de la denominada «Lista del sitio» (Osadny spisok) de 1618 y no solamente porque se trata de la edición de uno de los documentos más importantes para estudiar los Sobory de septiembre de 1618 y del verano de 1619. La propia presentación del texto de esta lista es muy significativa. Sus noticias están contrastadas y completadas por un gran conjunto de información extraída de muchas otras fuentes y repartida en siete apéndices ${ }^{39}$. Se ha publicado igualmente la Pistsovaya kniga (El Libro de los escribanos) de la región de Rostov ${ }^{40}$. Se trata de un complejo grupo documental importante y muy voluminoso de las descripciones territoriales realizadas por los escribanos, de la documentación sobre la reglamentación del régimen de la tierra y de las listas de contabilidad de los nobles provinciales para la región de Nizhni Nóvgorod, que fue publicado por el grupo de historiadores encabezado por A. V. Antónov ${ }^{41}$. Otro grupo de investigadores, encabezado por I. O. Tiuméntsev, ha realizado un proyecto muy interesante sobre la reconstrucción de los archivos del Período de los Tumultos. Se trata del archivo de campaña del hetmán Yan Sapega en 1608-1611, durante su estancia en el campamento de Dimitri II «El Falso» y más tarde al servicio del rey Segismundo III. Los documentos rusos del archivo puestos en orden cronológico y en relación a la asistencia al príncipe regional, son muy interesantes para estudiar las actividades de las asambleas representativas locales ${ }^{42}$.

En los años noventa del siglo xx fueron reeditados algunos relatos de extranjeros sobre Rusia ya publicados en el siglo xIx y primer tercio del xx (tales como las obras de Isaak Massa o Peter Petreius y otros autores). Poco después se actualizaron las normas de edición para tales textos: la publicación de la obra, en la

37. Stanislavsky, A. L.: Trudy po istorii Gosudareva Dvora v Rossii XVI-XVIII vekov. Moscú, 2004.

38. Antonov, A. V. y Baranov K. V. (eds.): Akty sluzhilykh zemlevladel'tsev XV-nachala XVII v. Sbornik dokumentov, vol. 1. Moscú, 1997; AnTonov, A. V. (ed.): Akty sluzbilykh zemlevladel'tsev XV - nachala XVII v. Sbornik dokumentov, vol. 2. Moscú, 1998; vol. 3. Moscú, 2002; vol. 4. Moscú, 2008. Toda la publicación incluye cerca de 2000 documentos, en su mayor parte no publicados con anterioridad.

39. Florya, B. N. y Eskin, Yu. M. (eds.): «Osadnyi spisok 1618 goda» en Gralia, I. (ed.): Pamiatniki istorii Vostochnoi Evropy. Istochniki xv-xvir vv. T. VIII / Ankhimiuk, Yu.V. y Pavlov, A. P. M., Varsovia, 2009.

40. Kadik, V. A. (ed.): Pistsovye materialy Rostovskogo uyezda XVII v. Moscú, 2012.

41. Antonov, A. V. et al. (eds.): Materialy po istorii Nizhegorodskogo kraya kontsa XVI-nachala XVII veka, Chast' 1-2. Moscú, 2015. 2012.

42. Tiumentsev, I. O. et al. (ed.): Russkiy arkbiv Yana Sapegi. 1608-1611 god. Volgogrado, 
VLADISLAV DMÍTRIEVICH NAZÁROV, PÁVEL YÚRIEVICH OUVÁROV Y VLADÍMIR ALEKSÁNDROVICH VÉDYUSHKIN LAS INSTITUCIONES RUSAS DE REPRESENTACIÓN DURANTE LOS SIGLOS XVI Y XVII EN EL CONTEXTO EUROPEO: UNA PERSPECTIVA HISTORIOGRÁFICA

mayoría de los casos en lengua original y acompañada por la traducción al ruso y por documentos de carácter biográfico y otros procedentes de archivos rusos y extranjeros, así como por un aparato crítico compuesto por extensos comentarios y artículos de investigación de muy diverso tenor. Estas fuentes contienen información directa e indirecta muy importante sobre los Zemskie Sobory, pero de especial interés son los términos empleados para traducir la noción de Sobor (Zemski Sobor) extraídos de la práctica y experiencia de sus países de origen. En este sentido destacan las obras del historiador sueco Yu. Videkind ${ }^{43}$, del capitán mercenario francés Jaques Margeret ${ }^{44}$, del alemán Heinrich von Staden (participante de la política de la Opríchnina $)^{45}$ y del anteriormente mencionado hetmán Yan Sapega (mejor dicho, de sus secretarios) ${ }^{46}$.

Estas y otras publicaciones de autores extranjeros subrayan la importancia y la actualidad de la búsqueda y publicación de fuentes extranjeras con información sobre los Sobory (aunque una colección de los documentos suecos sobre el sobor de 1613 fue editada ya a comienzos del siglo xx).

Por ello queremos destacar especialmente que el proceso de búsqueda y publicación del grueso de las fuentes rusas tenidas en cuenta hasta ahora para desarrollar el análisis y estudio de los Zemskie Sobory, así como de las obras de los extranjeros, está muy lejos de haber concluido. A ello hay que añadir que las fuentes ya conocidas, conservan todavía e igualmente su valor para los investigadores: sobre la base de estas fuentes continúan publicándose muchos artículos y capítulos en obras colectivas, pero aún no ha llegado a la comunidad científica una obra de síntesis comparable al libro de L. V. Tcherepnín.

A diferencia de anteriores generaciones de historiadores, el período de mediados y de la segunda mitad del siglo xvi no llama tanto la atención hoy en día de los investigadores. Se publican escasos artículos y notas sobre los Sobory de 1566, 1580 y 1584 (V. D. Nazárov, M. P. Lukichov, B. N. Florya, A. P. Pávlov, A. L. Korzinin). Pero la suerte historiográfica del Sobor de 1598 y de los posteriores es muy distinta. Por lo demás, todo el período de la primera guerra civil en Rusia, incluyendo la actividad de las asambleas representativas (a nivel estatal, regional o local), atrajo un elevado interés entre los científicos. El Sobor de 1598 fue estudiado

43. WideKINDI, Y.: Istoriya desiatiletnei shvedsko-moskovitskoy voyny. Moskva, 2000 / KHOROSHKeVICH A. L. y YANIN V. L. et al. (coords.).

44. Marjeret, J.: Sostoyanie Rossiyskoy imperii. J. Marjeret $v$ dokumentakh $i$ issledovaniyakh (Teksty, kommentarii, stat’i). Moscú, 2007 / Berelovich An., Nazarov V. D. y Ouvarov P. Yu. (coords.).

45. Staden, G.: Zapiski o Moskovii / Rychalovski, E. E. y Khoroshrevich, A. L. et al. (eds.), t. 1, Moscú, 2008; t. 2. Moscú, 2009.

46. Tiumentsev, I. O., Janicki, M., Tupikova, N. A. y Plotnikov, A. B. (ed.): «Dnevnik Yana-Petra Sapegi (1608-1611)» en Gralia, I. (ed.): Pamiatniki istorii Vostochnoi Evropy. Istochniki XV-XVII vv. T. IX / Tiumentsev, I. O. y Gralia, I. (eds.). Moscú; Varsovia, 2012. 
VLADISLAV DMÍTRIEVICH NAZÁROV, PÁVEL YÚRIEVICH OUVÁROV Y VLADÍMIR ALEKSÁNDROVICH VÉDYUSHKIN LAS INSTITUCIONES RUSAS DE REPRESENTACIÓN DURANTE LOS SIGLOS XVI Y XVII EN EL CONTEXTO EUROPEO: UNA PERSPECTIVA HISTORIOGRÁFICA

por A. P. Pávlov (en su libro sobre las luchas políticas de aquel tiempo) ${ }^{47}$, A. L. Lavréntiev y D. V. Liséitsev. La actividad institucional en relación a la autonomía del zemstvo a distintos niveles, su papel en la lucha militar y en los procesos políticos de 1609-1610 se analizan en el libro de I. O. Tiuméntsev ${ }^{48}$, así como en varios artículos.

En el libro de B. N. Florya se analiza un abanico de problemas muy parecido al que presentan las asambleas representativas de la capital y, por supuesto, de toda Rusia, desde el verano de 1610 hasta el invierno de 1611 (el destronamiento del zar Vasily Shuiski, el contrato de agosto sobre el reconocimiento del príncipe Vladislav como zar, los primeros pasos en la formación de la Primera Milicia Popular...), en el contexto de reacción de varios grupos de la sociedad rusa ante la intervención directa militar del rey de Polonia Segismundo $\mathrm{III}^{49}$. Los artículos de V. D. Nazárov, I. O. Tiuméntsev, Yu. M. Eskin, A. V. Beliakov y de otros investigadores están dedicados a los mismos aspectos del tema. Problemas análogos sobre la historia de las instituciones representativas durante la Segunda Milicia Popular y de las Milicias Unidas (ob'edinionnye opolcheniya) constituyen frecuentemente uno de los objetos de análisis en los libros dedicados al jefe militar de la Segunda Milicia Popular, el príncipe Dmitri Pozharski ${ }^{50}$, y la publicación de las Actas del Congreso conmemorativo organizado en Yaroslavl ${ }^{51}$.

En una gran parte de las investigaciones dedicadas al Sobor de 1613 se analiza, ante todo, el colectivo de los diputados (la serie de artículos de A. P. Pávlov publicados entre 2009-2014, los trabajos de A. A. Selin y los capítulos del libro de D. V. Liséitsev dedicados a los oficiales (diaki) participantes del Sobor) ${ }^{52}$, discutiéndose también como objeto de análisis la fecha de la Utverzhdiónnaya grámota y el problema de su identidad (A. P. Pávlov, A. A. Selin, D. V. Liséitsev y otros). El amplio espectro de facetas que suscita este tema, ligados con las candidaturas de los príncipes suecos para el trono ruso en 1611-1613, fue analizado por G. A. Zamiatin en su libro póstumo (que incluye los artículos no publicados con anterioridad) ${ }^{53}$. La reacción de la sociedad de Nóvgorod ante la toma de su ciudad en el verano de

47. Pavlov, A. P.: Gosudarev Dvor i politicheskaya bor'ba pri Borise Godunove. San Petersburgo, 1992.

48. Tiumentsev, I. O.: Smutnoe Vremia v Rossii nachala XVII stoletiya. Dvizhenie Lzhedmitriya II. Moscú, 2008.

49. Florya, B. N.: Pol'sko-litovskaya interventsiya v Rossiyu I russkoe obschestvo. Moscú, 2005.

50. Eskin, Yu. M.: Dmitri Mikhailovich Pozharski. Moscú, 2013.

51. Kozliakov, V. N. (ed.): Smutnoe vremia v Rossii v nachale XVII veka: poiski vykhoda. Moscú, 2012.

52. Liseitsev, D. V.: Prikaznaya sistema Moskovskogo gosudarstva v epokhu Smuty. Moscú, Tula, 2009.

53. Zamiatin, G. A.: Rossiya I Shvetsiya v nachale XVII veka. Ocherki politicheskoy $i$ voennoy istorii. San Petersburgo, 2008. 
VLADISLAV DMÍTRIEVICH NAZÁROV, PÁVEL YÚRIEVICH OUVÁROV Y VLADÍMIR ALEKSÁNDROVICH VÉDYUSHKIN LAS INSTITUCIONES RUSAS DE REPRESENTACIÓN DURANTE LOS SIGLOS XVI Y XVII EN EL CONTEXTO EUROPEO: UNA PERSPECTIVA HISTORIOGRÁFICA

1611 ha sido analizada en los artículos de A. A. Selin, G. M. Kovalenko y otros. Los Sobory de los primeros años de gobierno de Mijaíl Románov, en sus relaciones con los movimientos antigubernamentales y los levantamientos de los cosacos en 1613-1618, se han investigado en el libro de A. L. Stanislavski ${ }^{54}$.

El período posterior al Tiempo de los Tumultos se analiza en los estudios recientes siguiendo dos corrientes diferentes. La primera consiste en el análisis de la actividad de los Sobory en los asuntos de política exterior: las guerras con la República de las Dos Naciones, la posible incorporación de Azov en el estado Ruso (véanse los artículos de B. N. Floria). La segunda corriente se centra en la investigación de los Sobory de finales de los años cuarenta del siglo XviI en el contexto del análisis de las peticiones colectivas de las corporaciones locales de nobleza y de las prácticas electivas en las provincias (véanse los capítulos de los libros de V. N. Gláziev y T. A. Lápteva ${ }^{55}$, así como los artículos de D. A. Vysotski, I. L. Andréev, D. E. Gnevashev).

Las principales corrientes de estudio durante los últimos treinta años fueron desarrolladas en las ponencias del mencionado Congreso sobre las asambleas representativas en Rusia durante los siglos XVI y XVII ${ }^{56}$. Una de las corrientes más importantes se centra en la búsqueda y análisis de las fuentes primarias o en la realización de nuevas interpretaciones de las fuentes ya conocidas. D. V. Liseytsev analizó el documento nuevamente encontrado y relacionado con la información sobre el propósito y las decisiones del Sobor de 1614 (pamiat', enviada del Razriadny prikaz a Pomestny prikaz). O. Ya. Nozdrín comparó las noticias de Peter Petreius sobre los Sobory con las características de instituciones análogas de Suecia y de la República de las Dos Naciones hechas por el mismo Petreius y por sus contemporáneos. Una reseña sobre la información contenida en las hojas volantes alemanas de los primeros decenios del siglo XviI fue propuesta por la historiadora alemana K. Zoldat. Entre las fuentes rusas, las más estudiadas son las cartas (Utverzhdionnye gramoty) de los Sobory de 1598 y 1613, que ofrecen una mayor información sobre el contenido y número del cuerpo de los diputados (véase la ponencia de Ya. G. Solodkin sobre la Carta del Sobor de 1598).

Algunas ponencias estuvieron dedicadas a las formas de participación de la Iglesia rusa en las instituciones representativas. E. B. Emchenko sistematizó las

54. StAnislavsky, A. L.: Grazhdanskaya voina v Rossii XVII v. Kazachestvo na perelome istorii. Moscú, 1990.

55. Glaziev, V. N.: Vlast' y obschestvo na Yuge Rossii v XVII v. Vorónezh, 2001; LAPTEva, T. A.: Provintsial'noe dvorianstvo Rossii v XVII veke. Moscú, 2010.

56. Los resúmenes de las ponencias fueron publicados en: Doronin, A. V. y NazARov, V. D.: Soslovnoe predstavitel'stvo $v$ Rossii v kontekste evropeiskoy istorii. Vtoraya polovina XVI-seredina XVII vv. Mezhdunarodnaya nauchnaya konferentsiya 7-10 oktiabria $2013 \mathrm{~g}$. Tezisy dokladov. Moscú, 2013. El libro de las actas del Congreso está en prensa. 
VLADISLAV DMÍTRIEVICH NAZÁROV, PÁVEL YÚRIEVICH OUVÁROVY VLADÍMIR ALEKSÁNDROVICH VÉDYUSHKIN LAS INSTITUCIONES RUSAS DE REPRESENTACIÓN DURANTE LOS SIGLOS XVI Y XVII EN EL CONTEXTO EUROPEO: UNA PERSPECTIVA HISTORIOGRÁFICA

nociones que describen la estratificación social de la propia Iglesia, de la población seglar y de sus instituciones representativas, obtenida de los textos originales de Stoglavy Sobor (el libro de sus decisiones es conocido como Stoglav - «cien capítulos») de 1551. A. S. Usachiov analizó el número y la estructura de los eclesiásticos participantes de los Sobory (Osviaschionnye Sobory) en 1555 y 1566. Las formas de participación de los eclesiásticos de la catedral del Arcángel Miguel en el Kremlin durante las sesiones de los Sobory y en las ceremonias de las instituciones representativas, así como las noticias sobre los diputados de los sobory obtenidas del sinodik de la catedral del Arcángel Miguel (libro de memoria con los nombres de los muertos para conmemorarlos durante los servicios religiosos o en las oraciones particulares) fueron analizadas por D. G. Davidenko y Yu. D. Rýkov.

Entre los problemas que atraen más a los investigadores se encuentran los métodos de constitución de los Zemskie Sobory (las elecciones o nombramientos, el carácter de la participación de las instituciones del poder ejecutivo) y de su personal con los datos individuales sobre los diputados (su estatus social, posición económica, el cursus honorum de los que eran nobles). Los historiadores estudian cuestiones tales como los orígenes étnicos de cuatro participantes del Sobor de 1613 (A. V. Beliakov), el colectivo de los diputados elegidos para el mismo Sobor por la nobleza de Vólogda (D. E. Gnevashev) o biografías de dos diputados elegidos por la nobleza de Nizhni Nóvgorod (P. V. Chechenkov). A. P. Pavlov analizó la proporción entre nobles y participantes del Sobor de 1613 elegidos en distintas partes del país. Aspectos análogos para la historia de los Sobory de los años veinte a cuarenta del siglo XVII interesaron a T. A. Lápteva (su artículo basado en esta ponencia se publica en este dossier). La ponencia de V. N. Gláziev fue dedicada a los diputados nobles elegidos por las ciudades del sur de Rusia para los Sobory de los años cuarenta del siglo XVII, a sus relaciones con los poderes locales y con la población de la región así como a la influencia del mismo hecho de su participación en los Sobory durante su carrera posterior.

Se investigaba también el orden del día de las sesiones de los Sobory (incluyendo la problemática de las relaciones internacionales), así como las formas, prerrogativas y funciones de los Sobory en distintas etapas del Período de los Tumultos. A. I. Fíliushkin mostró la conexión entre los resultados de la Guerra Livona y algunas peculiaridades de la historia política de los países participantes -Rusia, Suecia y la República de las Dos Naciones-, incluyendo las instituciones representativas. B. N. Floria analizó la importancia y el carácter de los problemas financieros en los Zemskie Sobory de la primera mitad del siglo XVII. Las relaciones entre el Ejército de los Cosacos del Don con los Zemskie Sobory constituyeron el objeto de interés de N. A. Mininkov. V. D. Nazárov analizó las cuestiones de la formación y funcionamiento del sistema de nociones político-jurídicas que describen las instituciones representativas de varios niveles durante el siglo xvi y 
VLADISLAV DMÍTRIEVICH NAZÁROV, PÁVEL YÚRIEVICH OUVÁROV Y VLADÍMIR ALEKSÁNDROVICH VÉDYUSHKIN LAS INSTITUCIONES RUSAS DE REPRESENTACIÓN DURANTE LOS SIGLOS XVI Y XVII EN EL CONTEXTO EUROPEO: UNA PERSPECTIVA HISTORIOGRÁFICA

comienzos del xviI, las prácticas correspondientes, así como el surgimiento y la actividad del «consejo de toda la tierra» (primavera de 1611 - comienzos de 1613).

Otras ponencias estuvieron dedicadas a distintos aspectos de la historia de las asambleas representativas regionales y locales: los órganos de poder locales en las ciudades-fortalezas en la región de la frontera sur entre finales del siglo XvI y comienzos del siglo XVII (D. A. Liapin); acciones de los distintos grupos de la población de la parte sudoccidental del país a favor de la aventura de Demetrio I «el Falso» en 1604-1605 (I. O. Tiuméntsev); la política fiscal del gobierno del zar Vasily Shuiski, la reacción de la población ante el incremento de impuestos y la efectividad de las acciones de las instituciones representativas locales (V. A. Arakchéev); la composición del personal del consejo municipal de Vólogda según la documentación de comienzos del siglo Xvir (A. L. Griaznov, A. N. Guslístova); la composición del personal de las comisiones locales de testigos para los casos de tierras prestadas a condición del servicio militar en la región de Arzamás a finales del siglo XVI y comienzos del XVII (A. L. Khoroshkévich). Un episodio del verano de 1611, el intento del hetmán Yan Sapega de juramentar a los vecinos de Pereslavl-Zaleski, dio lugar a L. B. Súkina a analizar las peculiaridades de la existencia de algunas nociones políticas. La práctica del uso de los términos que describen la estructura de la población pechera de Nizhni Nóvgorod en los textos de la Milicia Popular de Kuzmá Minin y Dmitri Pozharski fue descrita por A.V. Morokhin y A. A. Kuznetsov. M. V. Moiséev analizó el conflicto entre el consejo municipal de Nizhni Nóvgorod y el poder ejecutivo provincial, encarnado en las personas de voevoda (gobernador de la provincia) y diak (oficial), originado por los gastos e impuestos en conexión con la salida de los embajadores persas (que permanecieron en Rusia desde 1608) y la embajada rusa a Persia y agravado por la participación activa de los prikazy de Moscú. El papel importante de las corporaciones de la nobleza de la región de Kaluga en los acontecimientos políticos fue subrayado por L. E. Morózova. A. A. Selin analizó un episodio importante de la historia de Veliki Nóvgorod: los resultados del plebiscito de 1614 sobre la prestación del juramento a favor del rey Gustavo II Adolfo de Suecia. Explicó estos resultados no solamente por las circunstancias de la política exterior, sino también por las peculiaridades de la estructura de población y de las instituciones representativas locales. E. N. Shveikóvskaya caracterizó las instituciones representativas regionales y, en especial, las locales del norte y nordeste de la parte europea de Rusia, acentuando dos momentos constituyentes: la estabilidad de las instituciones locales de autonomía y la libertad personal de los campesinos desde mediados del siglo xvi hasta mediados del xvir. El temario de las peticiones colectivas de los ciudadanos de la región de Vladimir después del Período de Tumultos fue analizado por O. N. Súslina. 
VLADISLAV DMÍTRIEVICH NAZÁROV, PÁVEL YÚRIEVICH OUVÁROVY VLADÍMIR ALEKSÁNDROVICH VÉDYUSHKIN LAS INSTITUCIONES RUSAS DE REPRESENTACIÓN DURANTE LOS SIGLOS XVI Y XVII EN EL CONTEXTO EUROPEO: UNA PERSPECTIVA HISTORIOGRÁFICA

Entre las ponencias dedicadas a la representación en Europa occidental y central, pocas tuvieron carácter general o comparativo. Además de la ya mencionada ponencia de Boytsov, la ponencia de N. A. Khachaturian dedicada al análisis comparativo de los modelos del parlamentarismo europeo medieval es significativa en este sentido. S. E. Fiodorov, basándose en las ideas reconsideradas de Otto Hintze, intentó construir una tipología de la representación europea. R. von Friedeburg comparó el estado de investigaciones sobre las relaciones de las élites con las asambleas de estado en Inglaterra, Francia y Alemania. J. I. Fortea Pérez parangonó el problema de la imposición de los eclesiásticos en el contexto de la representación en Francia y en España del siglo xviI.

Pero en su mayoría las ponencias sobre Europa occidental y central estuvieron dedicadas a los problemas concretos de la historia de la representación de unos u otros países: el Parlamento inglés como intermediario en las disputas entre los ciudadanos y sus señores (A. A. Anísimova), el problema de la elección de la lengua de trabajo en el funcionamiento de las instituciones representativas en Hungría ( $T$. P. Gusárova), los diputados de las Cortes de Castilla durante el siglo xvi (V. A. Védyushkin), la teoría y la práctica de la representación parlamentaria en Inglaterra durante el siglo xvi y comienzos del siglo XviI (O. V. Dmítrieva), el problema de la representación en Flandes y Brabante a finales del siglo xIv y en el siglo Xv, antes del surgimiento de los Estados Generales (A. A. Máyzlish), la diferencia entre el Parlamento escocés y el inglés (A. A. Palamarchuk), el funcionamiento de las instituciones imperiales de representación en sus esfuerzos de encontrar la salida de la vía muerta política en las difíciles condiciones de la Guerra de los Treinta Años (A. Yu. Prokópiev), las disputas parlamentarias y circumparlamentarias sobre la elección del heredero de Isabel I de Inglaterra (A. Yu. Serióguina), las pretensiones de los jueces del Parlamento de París en las funciones de representación (S. K. Tsatúrova), la resistencia de los estamentos y su legitimación en el estado de los habsburgos austriacos (A. Strohmeyer).

Algunos participantes del Congreso estudiaron la participación de la población rusa (y por supuesto ortodoxa) del Gran Ducado de Lituania (que ocupaba una posición intermedia entre Polonia, que pertenecía a la tradición occidental, y Rusia) en el funcionamiento de las asambleas representativas locales (séimiki).

La resulta del Congreso, posiblemente un poco desconsoladora, pero por lo menos veraz, es un reconocimiento de la gran complejidad que presentaban las instituciones representativas, mucho más complejas de lo que se creía con anterioridad. Si bien no se dieron respuestas concluyentes, se plantearon las cuestiones necesarias para entender mejor la esencia de los fenómenos analizados. A continuación ofrecemos las más significativas:

Primero. ¿Para qué se reúnen las instituciones representativas? ¿Cómo se relacionan el elemento divino y las directrices pragmáticas? Las elecciones y la toma 
VLADISLAV DMÍTRIEVICH NAZÁROV, PÁVEL YÚRIEVICH OUVÁROV Y VLADÍMIR ALEKSÁNDROVICH VÉDYUSHKIN LAS INSTITUCIONES RUSAS DE REPRESENTACIÓN DURANTE LOS SIGLOS XVI Y XVII EN EL CONTEXTO EUROPEO: UNA PERSPECTIVA HISTORIOGRÁFICA

de decisiones en general constituyen, para la época que se analiza, un asunto de Dios, y esto no es óbice para que al mismo tiempo se alcancen objetivos terrenales. En este sentido son muy curiosas y significativas un par de citas que el historiador español Juan Manuel Carretero Zamora da en su libro sobre las Cortes Castellanas a comienzos de la época moderna. De un lado, las palabras de los Reyes Católicos: «Nos vos mandamos procureys que elijan por sus procuradores de Cortes a don Gutierre de Fonseca e a Garçía Alonso de Ulloa». De otro, la carta de procuración de la ciudad de Toro para estas Cortes: «copo por suertes la dicha procuración a Garçía Alonso de Ulloa» ${ }^{57}$.

Segundo. Cómo se puede yuxtaponer la idea de la representación de los estamentos y grandes grupos sociales con la concepción moderna de historia social. Hoy se subraya el papel jugado por actores muy concretos: los políticos, los clanes familiares, las parcialidades y comunidades religiosas y profesionales, etc. (por ejemplo, la afinidad de los que entregan dotes a un mismo monasterio). Se expone una $u$ otra asamblea con funciones de representación como un fenómeno precisamente contextual dictado por situación concreta, un campo de lucha de los intereses y ambiciones de personas concretas. Entonces surge una pregunta: ¿en qué medida se pueden sumar estos intereses tan particulares a tendencias comunes de evolución de las estructuras y formas estatales?

Tercero. ¿En qué medida y cómo es posible unir distintas formas de participación de los súbditos en el gobierno y en la representación en los límites de un campo de investigación? La historiografía tradicional concentra su atención en las formas «verticales» de representación: las consultas de los monarcas con sus súbditos o el diálogo simbólico del monarca con «toda la tierra». Pero muy frecuentemente la representación funcionaba con más eficacia a nivel «horizontal», proveyendo no solamente el diálogo del poder con la sociedad, sino también la interacción regular entre territorios separados. El historiador neerlandés Wim Blockmans estudia estos problemas respecto a Europa Occidental desde hace mucho tiempo ${ }^{58}$, y los estudios sobre la actividad de la Segunda Milicia Popular durante el Tiempo de los Tumultos pueden servir como ejemplo en este sentido respecto a la historia de Rusia.

Los resultados más importantes del Congreso -y del desarrollo de los estudios sobre el tema en Rusia- son dos. De un lado, es un diálogo activo de los rusistas con los especialistas en la historia de Europa occidental (hasta ahora no muy habitual entre los historiadores rusos). De otro, es el reconocimiento de que, no obstante

57. Carretero Zamora, J. M.: Cortes, monarquía, ciudades: las Cortes de Castilla a comienzos de la época moderna, 1476-1515. Madrid-México, 1988, p. XV.

58. Véase, por ejemplo: Blockmans, W.: «Ob usloviyakh effektivnogo souchastiya v politicheskom upravlenii pri Starom Poriadke», Srednie veka, 75:3-4, 2014. C. 43-65. 
VLADISLAV DMÍTRIEVICH NAZÁROV, PÁVEL YÚRIEVICH OUVÁROVY VLADÍMIR ALEKSÁNDROVICH VÉDYUSHKIN LAS INSTITUCIONES RUSAS DE REPRESENTACIÓN DURANTE LOS SIGLOS XVI Y XVII EN EL CONTEXTO EUROPEO: UNA PERSPECTIVA HISTORIOGRÁFICA

la diferencia de los contextos políticos y de las tradiciones historiográficas, los investigadores rusos se mueven aproximadamente en la misma dirección que sus colegas en Europa Occidental y preguntan a sus fuentes primarias casi las mismas cuestiones. Este diálogo puede enriquecer el herramental así de los rusistas como de los historiadores que estudian la Europa Occidental.

\section{BibliogRAFÍA}

Aksakov, K. S.: Polnoe sobranie sochineniy, t. 1. Moscú, 1861.

Andreev, I. L. y Kozliakov, V. N. (eds.): «Prigovor Pervogo zemskogo opolcheniya (1611 goda, iyunia 30)» en Kozliakov, V. N. (ed.): Smutnoye vremia i zemskie opolcheniya v nachale XVII veka. Riazán, 2011, pp. 297-306.

Antonov, A. V. (ed.): «Prigovornaya gramota 1566 goda» en Antonov, A. V. (coord.): Russkiy diplomatariy, t. 10. Moscú, 2004, pp. 171-182.

Antonov, A. V. y Baranov, K. V. (eds.): Akty sluzhilykh zemlevladel'tsev XV-nachala XVII v. Sbornik dokumentov, vol. 1. Moscú, 1997.

Antonov, A. V. (ed.): Akty sluzhilykh zemlevladel'tsev XV-nachala XVII v. Sbornik dokumentov, vol. 2. Moscú, 1998; Vol. 3. Moscú, 2002; Vol. 4. Moscú, 2008.

Antonov, A. V. et al. (eds.): Materialy po istorii Nizhegorodskogo kraya kontsa XVInachala XVII veka. Chast' 1-2. Moscú, 2015.

Avaliani, S. A.: Zemskie sobory. Literaturnaya istoriya zemskikh soborov. $2^{a}$ ed., Odessa, 1916.

Blockmans, W.: «Ob usloviyakh effektivnogo souchastiya v politicheskom upravlenii pri Starom Poriadke», Srednie veka. 75:3-4. M., 2014. C. 43-65.

Bogoslovski, M. M.: Zemskoe samoupravlenie na russkom severe v XVII v, t. 1-2. Moscú, 1909-1912.

BoyTsov, M. A.: Velichie i smirenie, Ocherki politicheskogo simvolisma v srednevekovoy Evrope. Moscú, 2009.

BoyTsov, M. A.: «Soslovno-predstavitel'naya monarkhiya: oshibka v perevode?», Srednie veka, 75:3-4, 2014, pp. 66-78.

Carretero Zamora, J. M.: Cortes, monarquía, ciudades: las Cortes de Castilla a comienzos de la época moderna, 1476-1515. Madrid-México, 1988.

Chicherin, B. N.: O narodnom predstavitel'stve. Moscú, 1866.

Doronin, A. V. y Nazarov, V. D.: Soslovnoe predstavitel'stvo v Rossii v kontekste evropeiskoy istorii. Vtoraya polovina XVI-seredina XVII vv. Mezhdunarodnaya nauchnaya konferentsiya 7-10 oktiabria 2013 g. Tezisy dokladov. Moscú, 2013.

Eskin, Yu. M.: Dmitri Mikhailovich Pozharski. Moscú, 2013.

Fiodorov, S. E. (coord.): Korolevski dvor v Anglii XV-XVII vekov. San Petersburgo, 2011. Florya, B. N.: Pol'sko-litovskaya interventsiya v Rossiyu I russkoe obschestvo. Moscú, 2005. 
VLADISLAV DMÍTRIEVICH NAZÁROV, PÁVEL YÚRIEVICH OUVÁROV Y VLADÍMIR ALEKSÁNDROVICH VÉDYUSHKIN LAS INSTITUCIONES RUSAS DE REPRESENTACIÓN DURANTE LOS SIGLOS XVI Y XVII EN EL CONTEXTO EUROPEO: UNA PERSPECTIVA HISTORIOGRÁFICA

Florya, B. N. y Eskin, Yu. M. (eds.): «Osadnyi spisok 1618 goda» en Gralia, I. (ed.): Pamiatniki istorii Vostochnoi Evropy. Istochniki xv-XviI vv. T. VIII / AnkhImIUk, Yu. V. y Pavlov, A.P. (eds.). Moscú, Varsovia, 2009.

Glaziev, V. N.: Vlast' y obschestvo na Yuge Rossii v XVII v. Vorónezh, 2001.

Got'E, Ju.V. (ed.): Akty otnosiashchiesia k istorii zemskikh soborov. Moscú, 1909.

Gutnova, E. V.: Vozniknovenie angliyskogo Parlamenta: iz istorii angliyskogo obschestva i gosudarstva XIII veka. [Moscú], 1960.

Kadik, V. A. (ed.): Pistsovye materialy Rostovskogo uyezda XVII v. Moscú, 2012.

Karéev, N. I.: Pomest'e-gosudarstvo i soslovnaya monarkhiya srednikh vekov: ocherk razvitiya sotsial'nogo stroya y politicheskikh uchrezhdeniy $v$ Zapadnoi Evrope $v$ srednie veka. $3^{\text {a }}$ ed. San Petersburgo, 1913.

Khachaturian, N. A.: Vozniknovenie General'nykh Shtatov vo Frantsii. Moscú, 1976. Khachaturian, N. A.: Soslovnaya monarkbiya vo Frantsii XIII-XV vv. Moscú, 1989.

Khachaturian, N. A.: Vlast' i obschestvo v Zapadnoy Evrope v Srednie Veka. Moscú, 2008.

Khachaturian, N. A. (coord.): Dvor monarkha v srednevekovoy Evrope: yavlenie, model', sreda. Moscú, San Petersburgo, 2001;

Khachaturian, N. A. (coord.): Korolevski dvor v politicheskoy kul'ture srednevekovoy Evropy. Teoriya. Simvolika. Tseremonial. Moscú, 2004.

Khachaturian, N. A. (coord.): Sviaschennoe telo korolia. Ritualy i morfologiya vlasti. Moscú, 2006.

Kluchevsky, V. O.: «Sostav predstavitel'stva na Zemskikh soborakh Drevney Rusi (posviashchaetsia B. N. Chicherinu)», en KLuchevsky, V. O.: Sochineniya v deviati tomakh. T. VIII. Moscú, 1990, pp. 227-334.

Kolesnitsky, N. F. (coord.): Istoriya srednikb vekov. Moscú, 1980.

Koretsky, V. I., Lukichev, M. P. y Stanislavsky, A. L.: «Dokumenty o natsionalnoosvoboditelnoy borbe v Rossii v 1612-1613 gg.» en Lukichev, M. P.: Boyarskie knigi XVII veka: Trudy po istorii i istochnikovedeniyu. Moscú, 2004, pp. 198-234.

Kozliakov, V. N. (ed.): Smutnoe vremia v Rossii v nachale XVII veka: poiski vykhoda. Moscú, 2012.

Lapteva, T. A.: Provintsial'noe dvorianstvo Rossii v XVII veke. Moscú, 2010.

LAtKin, V. N.: Zemskie sobory Drevney Rusi, ikb istoriya i organizatsiya sravnitel'no s zapadnoevropeyskimi predstavitel'nymi uchrezhdeniyami. San Petersburgo, 1885.

LatKin, V. N.: Materialy dlia istorii zemskikh soborov XVII stoletia. San Petersburgo, 1884.

Liseitsev, D. V.: Prikaznaya sistema Moskovskogo gosudarstva v epokbu Smuty. Moscú, Tula, 2009.

Lublinskaya, A. D.: French absolutism: the crucial phase 1620-1629. Londres, Cambridge University Press, 1968.

Lublinskaya, A. D.: La crisis del siglo XVII y la sociedad del Absolutismo / prólogo de Josep Fontana. Barcelona, 1979.

Liubomirov, P. G.: Ocherki istorii nizhegorodskogo opolcheniya 1611-1613 gg. Petrogrado, 1917. 
VLADISLAV DMÍTRIEVICH NAZÁROV, PÁVEL YÚRIEVICH OUVÁROVY VLADÍMIR ALEKSÁNDROVICH VÉDYUSHKIN LAS INSTITUCIONES RUSAS DE REPRESENTACIÓN DURANTE LOS SIGLOS XVI Y XVII EN EL CONTEXTO EUROPEO: UNA PERSPECTIVA HISTORIOGRÁFICA

MarJeret, J.: Sostoyanie Rossiyskoy imperii. J. Marjeret v dokumentakb i issledovaniyakh (Teksty, kommentarii, stat'i). Moscú, 2007 / Berelovich An., Nazarov V. D. y Ouvarov P. Yu. (coords.)

Morozov, B. N. y Stanislavsky, A. L. (eds.): «Povest’ o Zemskom sobore 1613 goda», Voprosy istorii, 5, 1985, pp. 89-96.

Nosov, N. E.: Stanovlenie soslovno-predstavitel'nykh uchrezhdeniy v Rossii. Leningrado, 1969.

Novosel'sKI, A. A.: Bor'ba Moskovskogo gosudarstva s tatarami v pervoi polovine XVII veka. Moscú-Leningrado, 1948.

Ouvarov, P. Yu.: «Parizhski universitet I mestnye interesy (konets XIV - pervaya polovina XV v.», Srednie veka, 54, 1991, pp. 55-71.

Pavlov, A. P.: Gosudarev Dvor i politicheskaya bor'ba pri Borise Godunove. San Petersburgo, 1992.

PÁvlov-Silvansky, N. P.: Feodalizm v Drevney Rusi. San Petersburgo, 1907.

PiskorsKi, W. K.: Kastil'skie kortesy v perekhodnuyu epokhu ot srednikh vekov k novomu vremeni (1188-1520). Kiev, 1897.

Piskorski, W.: Las Cortes de Castilla en el período de tránsito de la Edad Media a la Moderna: 1188-1520. Barcelona, 1977.

Platonov, S. F.: Ocherki po istorii Smuty v Moskovskom gosudarstve XVI-XVII vekov. San Petersburgo, 1899.

Platonov, S. F.: «K istorii moskovskikh zemskikh soborov», Zhurnal dlia vsekh, 3, 1905.

Porchnev, B.: Les soulèvements populaires en France de 1623 à 1648. París, 1963.

Sergeevich, V. I.: «Zemskie sobory v Moskovskom gosudarstve», en Bezobrazov, V. P. (coord.): Sbornik gosudarstvennykh znaniy. T. 2. San Petersburgo, 1875.

Smirin, M. M.: Die Volksreformation des Thomas Münzer und der grosse Banernkrieg. Berlín, 1952.

SMIrnov P. P.: Posadskie liudi i ikh klassovaya bor'ba do serediny XVII v., t. 1-2. Moscú-Leningrado, 1947, 1948.

SHIshKIN V. V.: Korolevski dvor I politicheskaya bor'ba vo Frantsii XVI-XVII vv. San Petersburgo, 2004.

SHмidt, S. O.: Stanovlenie rossiyskogo samoderzhavstva. Moscú, 1973.

Staden, G.: Zapiski o Moskovii / Rychalovski, E. E. y Khoroshkevich, A. L. et al. (eds.), t. 1, Moscú, 2008; t. 2. Moscú, 2009.

Stanislavsky, A. L.: Grazhdanskaya voina v Rossii XVII v. Kazachestvo na perelome istorii. Moscú, 1990.

Stanislavsky, A. L.: Trudy po istorii Gosudareva Dvora v Rossii XVI-XVII vekov. Moscú, 2004.

Stratonov, I. A.: Zametki po istorii zemskikh soborov Moskovskoy Rusi. Kazán, 1912.

TCherepnin, L. V.: Zemskie sobory Russkogo gosudarstva v XVI-XVII vv., Moscú, 1978.

Tikhomirov, M. N.: «Pskovskoe vosstanie 1650 goda» en Tikhomirov, M. N.: Klassovaya bor'ba v Rossii XVII v. Moscú, 1969, pp. 23-138. 
VLADISLAV DMÍTRIEVICH NAZÁROV, PÁVEL YÚRIEVICH OUVÁROV Y VLADÍMIR ALEKSÁNDROVICH VÉDYUSHKIN LAS INSTITUCIONES RUSAS DE REPRESENTACIÓN DURANTE LOS SIGLOS XVI Y XVII EN EL CONTEXTO EUROPEO: UNA PERSPECTIVA HISTORIOGRÁFICA

Tikномirov, M. N.: «Dokumenty Pskovskogo vosstaniya i Zemskogo Sobora 1650 goda» en Tikhomirov, M. N.: Klassovaya bor'ba v Rossii XviII v. Moscú, 1969, pp. 234-332.

Tiumentsev, I. O.: Smutnoe Vremia v Rossii nachala XVII stoletiya. Dvizhenie Lzhedmitriya II. Moscú, 2008.

Tiumentsev, I. O. et al. (ed.): Russkiy arkhiv Yana Sapegi. 1608-1611 god. Volgogrado, 2012.

Tiumentsev, I. O., Janicki, M., Tupikova, N. A. y Plotnikov, A. B. (eds.): «Dnevnik Yana-Petra Sapegi (1608-1611)» en Gralia, I. (ed.): Pamiatniki istorii Vostochnoi Evropy. Istochniki XV-XVII vv, t. IX / Tiumentsev, I. O. y Gralia, I. (eds.). Moscú; Varsovia, 2012.

Tsaturova, S. K.: Ofitsery vlasti: Parizhski parlament v pervoy treti XV v. Moscú, 2002.

Tsaturova, S. K.: Formirovanie instituta gosudarstvennoi sluzhby vo Frantsii XIII-XV vekov. Moscú, 2012.

Tsaturova, S. K.: «Skandal v koridorakh vlasti vo Frantsii XIV v.», en VARIASH, O. I. (coord.): Pravo v srednevekovom mire. Moscú, 1996, c. 221-269.

VladimirskiY-Budanov, M. F.: Obzor istorii russkogo prava. Kiev, 1886.

Vedyushinin, V.: «La España de los historiadores rusos (Segunda mitad del siglo XIX comienzos del siglo xx)», Eslavística Complutense, 14, 2014, pp. 107-114.

VEDIUshrin, V. A.: «Dvor Filippa III glazami sovremennika», Novy filologuicheski vestnik, 2(29) - como se indica en esta revista (tomo segundo para 2014 y 29 en general). Si no es posible - 29:2, 2014, pp. 129-139.

Widekind, Y.: Istoriya desiatiletnei shvedsko-moskovitskoy voyny. Moscú, 2000 / Khoroshkevich A. L. y Yanin V. L. et al. (coords.).

ZaGoskin, N. P.: Istoriya prava Moskovskogo gosudarstva, t. 1. Kazán, 1877.

Zamiatin, G. A.: Rossiya I Shvetsiya v nachale XVII veka. Ocherki politicheskoy i voennoy istorii. San Petersburgo, 2008. 
